Pontificia Universidade Católica $_{\text {do Rio de janeiro }}$

Katia Fabiola Canepa Vega

\title{
Beauty Technology \\ as an Interactive Computing Platform
}

TESE DE DOUTORADO

Thesis presented to the Programa de Pós-Graduação em Informática of the Departamento de Informática, PUC-Rio as partial fulfillment of the requirements for the degree of Doutor em Informática.

Advisor: Prof. Hugo Fuks Co-Advisor: Prof. Patricia Flanagan

Rio de Janeiro

February 2014 
Katia Fabiola Canepa Vega

\title{
Beauty Technology as an Interactive Computing Platform
}

Thesis presented to the Programa de Pós Graduação em Informática of the Departamento de Informática do Centro Técnico Científico da PUC-Rio, as partial fulfillment of the requirements for the degree of Doutor.

\author{
Prof. Hugo Fuks \\ Advisor \\ Departamento de Informática - PUC-Rio \\ Prof. Bruno Feijó \\ Departamento de Informática - PUC-Rio \\ Prof. Alberto Barbosa Raposo \\ Departamento de Informática - PUC-Rio \\ Dr. Denise Del Re Filippo \\ UERJ \\ Prof. Fernando Reiszel Pereira \\ UERJ \\ Prof. José Eugenio Leal
}

Coordinator of the Centro Técnico Científico - PUC-Rio

Rio de Janeiro, February $26^{\text {th }}, 2014$ 


\section{Katia Fabiola Canepa Vega}

Katia Vega is a PhD Candidate in Computer Science at the Department of Informatics from the Pontifical Catholic University of Rio de Janeiro (Brazil). She got her master degree at the same department. She is a System and Informatics Engineer graduated from the National University of San Marcos (Peru). She was a Research Assistant in the Wearables Lab at the Hong Kong Baptist University. Founder and Trainer of Soluciones Racionales (Peru).

Bibliographic data

Canepa Vega, Katia Fabiola

Beauty Technology as an Interactive Computing Platform / Katia Fabiola Canepa Vega ; advisor: Hugo Fuks, co-advisor: Patricia Flanagan. - 2014.

81 f. : il. (color.) ; $30 \mathrm{~cm}$

Tese (doutorado)-Pontifícia Universidade Católica do Rio de Janeiro, Departamento de Informática, 2014.

Inclui bibliografia

1. Informática - Teses. 2. Beauty technology. 3. Computação vestível. 4. Maquiagem condutiva. 5. Tech nails. 6. FX e-makeup. 7. Cílios condutivos. 8. Segunda pele. Computação invisível. 9. Interação humano computador. I. Fuks, Hugo. II. Flanagan, Tricia. III. Pontifícia Universidade Católica do Rio de Janeiro. Departamento de Informática. IV. Título. 


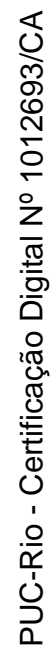

To my mom Lidis 


\section{Acknowledgments}

To my advisor, Professor Hugo Fuks, an incredible mentor. I am so proud to work closely with such a visionary professor and I could never thank him enough for showing me the real meaning of osadia.

To the Thesis Committee for their significant contributions in the refinement of this work.

The PUC -Rio for supporting and believing in my project. To the agency CNPq for providing the funding that allowed me to undertake this research.

To Felipe Esteves, the first person who said that he would use this technology, and for showing me the unlimited possibilities of it. I hope sometime I would find the secret of his great strength. To Hugo Rojas, for sharing his chemical knowledge and opening the doors of the EQA Lab for the development of conductive eyelashes. To Patricia Flanagan and HKBU for giving me the opportunity to be in Hong Kong and sharing their vision of Fine Arts. To Dim Sum Labs for adopting me, and being my inspirational headquarter overseas. To Seeed Studio for showing me what is to be a real Maker. To my colleagues, Débora Cardador and Wallace Ugulino, for the stimulating discussions and endless collaborations. To Carla Panisset for her invaluable lessons in media training.

To the collaborators in Beauty Technology applications. Superhero: EQA (Chemical Lab), Jonathan James (Costume Designer). Arcana: Larca Meicap (character concept and makeup), Maribel Tafur (video). Blinklifier: Tricia Flanagan (artist), EQA (chemical lab), Dicky Ma (photo), Gutekunst/Frey (video). AquaDJing: Maribel Tafur (sound design and performer), Congo Sanchez (performer). Sentido Aware: Elen Nas (sound design and performer), Camaleão Produtora (video). Winkymote: Abel Arrieta (hardware), Felipe Esteves (evaluation), Natalia Bruno (product design). Kinisi: Abel Arrieta (hardware), Larca Meicap (character concept and makeup), Juan Carlos Yanaura (direction and edition), Gabriella Chávez (model), Maribel Tafur (music), Aluzcine (production).

To the family you choose, my friends near and far: Maribel Tafur, Milagros Portilla, Diego Leonardo, Viviana Valiente, Geraldine Ishiguro, Maju Benites, Paola García, Bruno Gadelha, Álan Livio, Marcos Junior, Eduardo Cruz and An- 
drew Richmond, for teaching me what true friendship is and keeping me sane.

To my father, my brothers and my Aunt Mary for their love without borders and the encouragement to keep going.

To my mom, for her infinite love. To her I dedicate this thesis. 


\section{Abstract}

Vega, Katia; Fuks, Hugo (Advisor); Flanagan, Patricia (Co-advisor). Beauty Technology as an Interactive Computing Platform. Rio de Janeiro, 2014. 81p. PhD Thesis - Departamento de Informática, Pontifícia Universidade Católica do Rio de Janeiro.

This work introduces the term Beauty Technology as an emergent field in Wearable Computing. Wearable Computing had changed the way individuals interact with computers, intertwining natural capabilities of the human body with processing apparatus. Beauty Technology transforms our body in an interactive platform by hiding technology into beauty products for creating muscle based interfaces that don't give the wearer a cyborg look. Several applications of beauty technologies used in everyday products and shown in exhibitions expose the feasibility of this technology. Conductive Makeup, Beauty Tech Nails, FX e-makeup and Hairware exemplify Beauty Technology prototypes.

\section{Keywords}

Beauty Technology; Wearable Computing; Muscle Based Interface. 


\section{Resumo}

Vega, Katia; Fuks, Hugo (Orientador); Flanagan, Patricia (Coorientador). Beauty Technology como uma plataforma de computação interativa. Rio de Janeiro, 2014. 81p. Tese de Doutorado - Departamento de Informática, Pontifícia Universidade Católica do Rio de Janeiro.

Este trabalho introduz o termo de Beauty Technology como um campo emergente na computação vestível. A Computação Vestível tem mudado a maneira de como as pessoas interagem com computadores, entrelaçando dispositivos computacionais com as capacidades naturais do corpo humano. A Beauty Technology transforma o corpo numa plataforma de interação, escondendo a tecnologia em produtos de beleza para a criação de interfaces baseadas em movimentos musculares sem dar ao usuário um visual de ciborgue. Para mostrar a viabilidade desta tecnologia, várias aplicações de Beauty Technology foram desenvolvidas em produtos de uso diário e mostradas em exposições. Conductive Makeup, Beauty Tech Nails, FX e-makeup e Hairware exemplificam os protótipos de Beauty Technology.

\section{Palavras-chave}

Beauty Technology; Computação Vestível; Muscle Based Interface. 


\section{Table of Contents}

1 Introduction 14

1.1. Overview 14

$\begin{array}{ll}\text { 1.2. Motivation } & 16\end{array}$

1.2.1. Invisible Computer 16

$\begin{array}{ll}\text { 1.2.2. Wearable Computing } & 17\end{array}$

$\begin{array}{lr}\text { 1.2.3. Cyborg Fashion } & 19\end{array}$

1.3. Thesis Organization $\quad 21$

2 Related Work $\quad 23$

2.1. The Human Body as an Interactive Platform 23

2.2. Interfaces on Skin 25

2.3. Interfaces for Sensing Blinking 26

2.4. Interfaces on Facial Muscles 28

$\begin{array}{ll}\text { 2.5. Interfaces on Fingertips } & 29\end{array}$

3 Beauty Technology 32

3.1. On Body Technologies 32

3.2. Muscle Based Interfaces $\quad 34$

3.3. Beauty Technology as an Interactive Computing Platform 35

4 Facial Expression $\quad 37$

4.1. Conductive Makeup $\quad 37$

4.1.1. Conductive Makeup 39

4.1.2. Conductive Makeup Applications: Electronic Divas 41

4.1.3. Lessons Learned 43

4.1.4. Conclusion and Future Work 44

4.2. FX e-makeup $\quad 45$

4.2.1. FX e-makeup $\quad 46$

4.2.2. FX e-makeup applications $\quad 49$

4.2.3. Lessons Learned 51

4.2.4. Conclusion and Future Work 52 
5. Arm/Hand Movement 54

5.1. Beauty Tech Nails $\quad 54$

5.1.1. Beauty Tech Nails with RFIDs

5.1.2. Prototype Design 56

5.1.3. Interactive Possibilities and Applications $\quad 57$

5.1.4. Conclusion and Future Work 58

6 Conclusions and Future Work $\quad 61$

6.1. Contributions 62

6.2. Future Work 63

6.3. Published Work 64

6.3.1. Publications 64

6.3.2. Awards 65

6.3.3. Exhibitions and Demos 65

6.3.4. Future presentations 66

6.3.5. Media Coverage 66

$\begin{array}{ll}\text { References } & 76\end{array}$ 


\section{List of Figures}

Figure 1. Evolution and Hock and Eyes [14]. 18

$\begin{array}{ll}\text { Figure 2. LED eyelashes [15]. } & 18\end{array}$

Figure 3.Popular Science Magazine [18]. 20

Figure 4. Locutus, Star Trek [23]. 21

Figure 5. Taxonomy of Body Movements [24]. 22

Figure 6. Skeleton model with 20 joints [32]. 24

Figure 7. MC10 Inc.'s flexible electronic sensors are about the size of a postage stamp [17]. 25

Figure 8. Goggles with electrodes for sensing blinking [47]. 26

Figure 9. Blinking detection by means of difference images: 27

Figure 10. Facial Muscles Interfaces. 29

Figure 11. NailDisplay, OLED display on the fingernail [59]. 30

Figure 12. Pingu, fingering for gesture recognition [62]. 30

Figure 13. Abracadabra, wristwatch controlled by magnets on fingertips [64]. 31

Figure 14. Body Technologies by their locality. 33

Figure 15. Multilayer classification of devices on the Skin [11]. 34

Figure 16. Taxonomy of Body Movements [24]. 35

Figure 17. Adapted from "Taxonomy of Body Movements" [24]. 37

Figure 18. Conductive Makeup blinking interface. 39

Figure 19. Metalizing black fake eyelashes. $\quad 40$

Figure 20. Arcana performance with conductive makeup. 42

Figure 21. Superhero blinks for levitating objects. 44

Figure 22. Percentage of participants who succeeded in activating

the target action units [104]. $\quad 47$

Figure 23. FX e-makeup interface. a) Sensors connected on muscles,

b) eyebrow sensor, c) eyelid sensor, d) smile sensor, e) closing lips sensor. $\quad 48$

Figure 24. Kinisi. $\quad 50$

Figure 25. Winkymote, an infrared-controlled interface for individuals

with quadriplegic disability. $\quad 51$

Figure 26. Adapted from "Taxonomy of Body Movements" [24]. 54

Figure 27. Interaction between Beauty Tech Nail and the reader. 55

Figure 28. Prototyping Beauty Tech Nails. Gel Nail process. 57

Figure 29. Twinkle Nails, non-contact piano playing 58 
Figure 30. Unusual interactions. 30.1. AquaDJing, mixing tracks touching water surface. 30.2. Sentido Aware, Opera singer playing tracks and sound effects touching into the water.

Figure 31. Gimmickiano, wearable that recognizes RFID nails. 


\section{List of Tables}

Table 1. Black Metalized Fake Eyelashes Electrochemical Process 


\section{Introduction}

Wearable Computing changed the way individuals interact with computers, intertwining natural capabilities of the human body with processing apparatus [1]. However, most of this technology that has been designed just for clothing or accessories is still flat and rigid showing its electronic components. Beauty Technology moves this technology to the body's surface to create an interactive computing platform where electronic components are unnoticed by embedding them into aesthetic adornments. This section presents an overview of Beauty Technology, the document organization and the project motivation.

\subsection{Overview}

This thesis introduces Beauty Technology, a novel field in Wearable Computing that embeds electronic components into beauty products and applies them to the body's surface to sense muscle movements as inputs to trigger devices, thus, creating a new interactive computing platform.

What if we could activate the world with just a blink? Make a left wink and turn the lights on; check your last emails with your right wink. Beauty Technology proposes the use of Conductive Makeup to sense voluntary blinking. It connects sensors and actuators using conductive materials that stick to the skin as welldefined eyeliner. Black false eyelashes are chemically metalized to act as switches for sensing blinking. Blinklifier and Arcana are examples of Beauty Tech products that communicate by amplifying blinking and creating gestures to change light patterns, activate different music tracks and display different images, respectively. Superhero is another example of the use of conductive false eyelashes and makeup to levitate objects by blinking.

Could your skin act as an interface? A facial expression conveys an emotion but what if a voluntary expression could trigger an electronic device? FX emakeup, a Beauty Technology prototype based on traditional FX makeup combined with sensors that can sense muscle movements as the skin folds on the musculature of the face. Winkymote is an infrared remote control placed near the eye to help people with quadriplegic disabilities control the electronics around 
them. Kinisi uses FX e-makeup to hide sensors and LEDs on the face, which light in different patterns triggered by the facial muscles.

Imagine that you don't need a card for opening your door, or for paying your bus ticket. Imagine that you don't need to carry any ticket for going to a movie session. Go and shop at the supermarket or rent a book at the library without a wallet or ID card, just point and pay for it, everything at your fingertips: your nails. Beauty Technology Nails embed technology components into fake nails in order to interact with the ambient in different ways. Beauty Tech Nails provide fashionable, inexpensive and wireless devices attached to fingernails, with no need for powered external components. They have embedded RFID tags in order to create actuators to communicate with the wearer, other objects and the virtual world. For example, instead of using a staff card to open the office door, a secret combination of finger movements with RFID nails could identify employees and grant them access as demonstrated in the project called Abrete Sesamo (Open Sesame) [2]. The invisible tracking advantages of RFID tags brought positive applications in different contexts such as retail automation, bridging the gap between digital networks and the physical world [4].

Humans convey over two-thirds of their ideas and feelings through the body, producing up to 700,000 physical signs, where 1000 are bodily postures, 5000 are hand gestures, and 250,000 are facial expressions [5]. We are intimately familiar with our own bodies from birth and due to human agency, we are aware of the initiating, executing, and controlling of our own body. Moreover, knowing that we have roughly $2 \mathrm{~m}^{2}$ of skin, placing sensors onto the skin for sensing physical changes seems to be the obvious next step in Wearable Computing. This work analyses micro and macro body movements to propose interfaces that react to voluntary movements. In this way, a voluntary blinking could be sensed by Conductive Makeup, voluntary facial movements such as closing eyes, raising an eyebrow, smiling and closing the lips could be sensed by FX e-makeup and finger approximation by Beauty Tech Nails.

From the very first civilizations to the present day, beauty products have been used by every society to disguise, enhance, highlight, alter and decorate the body. Given their acceptance and availability, this project uses beauty products to design interfaces on the body surfaces. It explores different materials for embedding electronics such as fake nails and FX makeup. For example, to create a new kit of innovative materials to the interface, eyelashes were metalized using a chemical process. 


\subsection{Motivation}

One of the main motivations of this project lies in the concept of the invisible computer. By hiding technology into everyday objects, they will communicate with the environment, process the user's intentions and store daily life activities. Another motivation is that Wearable computers have been increasingly developed in the last few years and currently are considered as a key future trend. They are traditionally placed on clothing and accessories, with the surface of the body being the next logical destination. Finally, influenced by the invisible computer, the cyborg fashion is another motivation. "Wearables" may remind us of the appearance of a cyborg - usually seen in sci-fi movies, with electronic components appearing on their face - but that is not the only role a cyborg can play.

\subsubsection{Invisible Computer}

Weiser [5] envisions a ubiquitous computing paradigm where technology assists us in our everyday lives, functioning invisibly and unobtrusively: "The most profound technologies are those that disappear. They weave themselves into the fabric of everyday life until they are indistinguishable from it." This statement has been a source of inspiration for many and still is an important guideline in Ubiquitous Computing, changing the idea that a computer is needed for computing. However, it is clear that integrating new technologies into the very fabric of everyday life is not realized in Ubiquitous Computing. Despite a great deal of development in Ubicomp systems, they haven't disappeared yet or become an 'unremarkable' feature of everyday life [6].

The major challenge of the Disappearing Computer paradigm is the development of new computational devices that integrate technology into everyday experiences in a way that supports natural and intuitive interaction [6]. When this goal is reached, these pieces of technology will gather data and process it for us, without us becoming consciously aware of the fact they're doing it. This will be possible by designing technologies with simplicity: invisible technologies that break the barrier of complexity, making them fit the task so well that the tool becomes a part of the task. When this is accomplished, human beings will feel that technology is an extension of their own body, and then, they will not be more aware that the technology is there [7]. 


\subsubsection{Wearable Computing}

The idea behind augmenting human capabilities through Wearable Devices has a long history starting with eyeglasses and pocket watches, created to augment sight and to track time [8]. In 1665, Robert Hooke [9] proposed the idea of adding "artificial organs" to our natural ones in order to improve senses of hearing, smelling, tasting, and touching. Today, Wearable Computing looks for opportunities to use body integrated computational and sensory devices in a way that inextricably intertwine human and computer [1].

Developments in novel materials are improving the ease of embedding technologies into fabrics as well as the use of implantable devices and biosensors [10]. In the near future, nanotechnology, biotechnology, information technology and cognitive technology will converge - making it possible to have wearables with their own power generation, flexible displays and electric-responsive materials [11]. Even more, the miniaturization and availability of electronic components have made possible the wide-spread of wearable computing, moving from the realm of science fiction to the marketplace in areas such as fashion, health, and wellness for the aging and disabled.

The fact that not only big software companies such as Google, Motorola, Apple and Microsoft are creating wearable tech, but fashion industry icons like Nike and Adidas are also making significant investments in this area is an indicator that wearables will become mainstream devices in the forthcoming years [10]. Google Glass [12] could be one of the clearest examples of wearable devices that have garnered great attention in recent years. These glasses embed a display coupled with a location awareness sensor, illustrating the potential of wearable computing technologies to tap into apps and enable the user to access information. Start-ups are also investing in wearables technologies. For example, Pebble [13] rethought a wristwatch designed to interact with an iPhone. In a short period of time the Pebble has broken records for the crowdfunding platform Kickstarter for the amount of money raised: over seven million in a matter of weeks.

Besides this revolution in wearable gadgets at the marketplace, fashion designers have the chance to interact with technology and play a key role in wearable computers. But wearable computers won't be exclusive for fashion designers. It is expected that people with different skills will get together and share their knowledge to create their own prototypes. This opens the "DIY Fashion" gateway 
for makers, enthusiasts and researchers in different fields to design their own wearables [11].
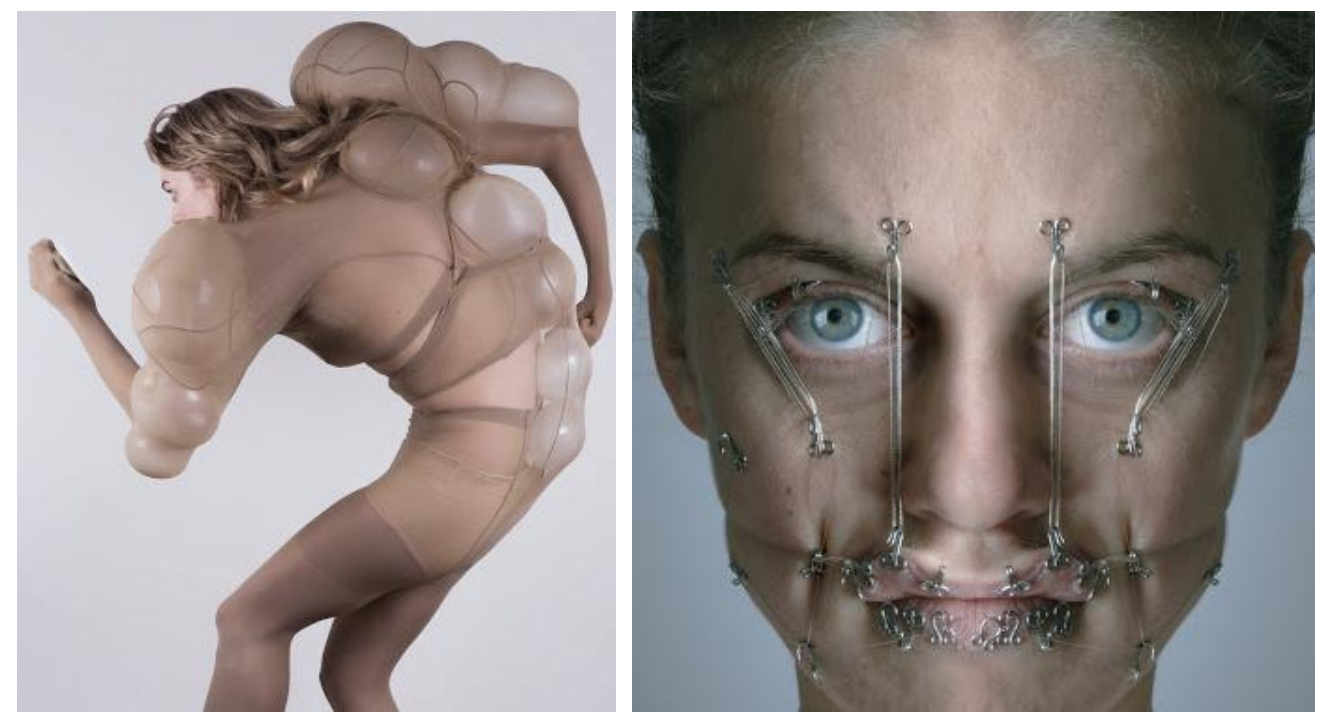

Figure 1. Evolution and Hock and Eyes [14].

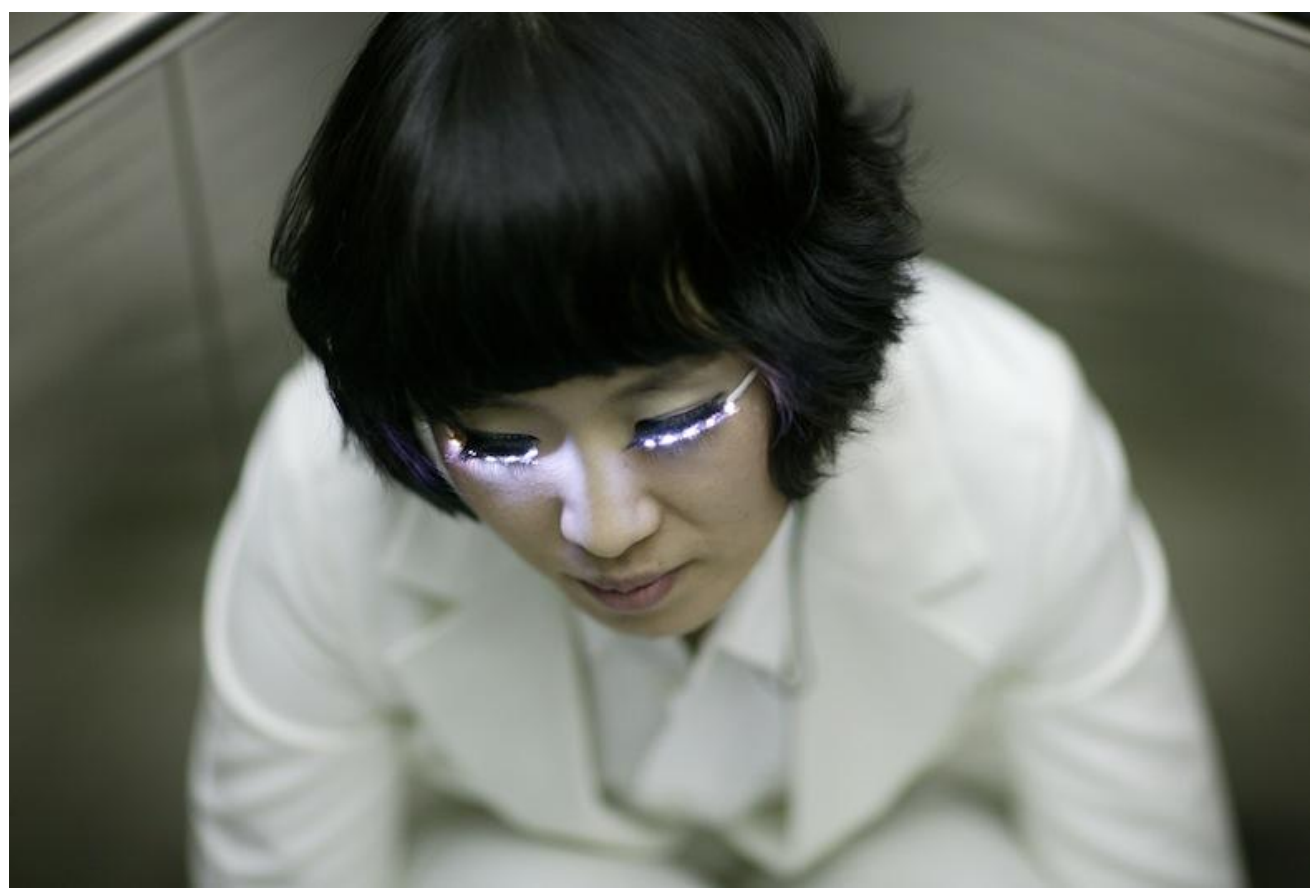

Figure 2. LED eyelashes [15].

Wearables are already causing a rethinking of the boundaries of the body. Lucy McRae [16] envisions future possibilities of merging technology and the human body. Through artistic showcases, she redefines the body by mimicking its musculature, thus, changing the perception of our own body to create futuristic human shapes (Figure 1). Along these lines, LED eyelashes [15] expose the de- 
sire of many Asian women to show more of their eyes by lighting the eyelashes that follow pupil and head movements (Figure 2).

\subsubsection{Cyborg Fashion}

The word cyborg is a mash up of the phrase "cybernetic organism" and was coined more than 50 years ago in an academic article on the possible future needs for humans surviving in extra-terrestrial environments [17]. It described the advantages of a self-regulatory human-machine system, adjusted to the space environment, in which "robot-like problems are taken care of automatically and unconsciously, leaving man free to explore, to create, to think, and to feel" [17]. Despite some critical reviews like the one in Popular Science [18] that exposed the image of the "tomorrow's man" with technological gadgets around his body (Figure 3), the term cyborg is considered by most futuristic predictions to present how human's capability will be augmented through technology. For example, The Singularity, which is a theoretical point in time where technology will have progressed to the point that humans will augment their bodies and increase their life spans through mechanical enhancements, predicts that humans will become cyborgs in 2045 [19].

Literature, art and film always devise possible futures that new technologies might bring. Their predictions and projections not only shape ways of imagining the future of humanity, but have also prepared us to adapt to and gradually accept the ideas of technologically mediated existence, thus incorporating them into the reality we share today [20]. Most notably Martin Caidin's novel called Cyborg (1972) was adapted as TV's Six Million Dollar Man, in which a former astronaut with bionic implants works for a fictional government office [21]. By the 1980s, when the idea of direct human interface with computers was taken as a serious possibility, the "cyberpunk" writers were littered with imaginary cyborgs. Prosthetic devices to enhance and extend the range and function of human vision are probably the most pervasive of cyborg systems in recent science fiction. Locutus had the Borg's cybernetic devices implanted throughout his body in Star Trek: The Next Generation (Figure 4). Terminator, Robocop and Darth Vader are fictional cyborgs with a metal endoskeleton, memory assistance by on-board computer and cybernetic limbs. Science-fiction movies and the depiction of humancomputer interaction and communication have, of necessity, been closely intertwined. Cross-cultural sci-fi and $\mathrm{HCl}$ trends, patterns, and issues remain largely unexplored [22]. 


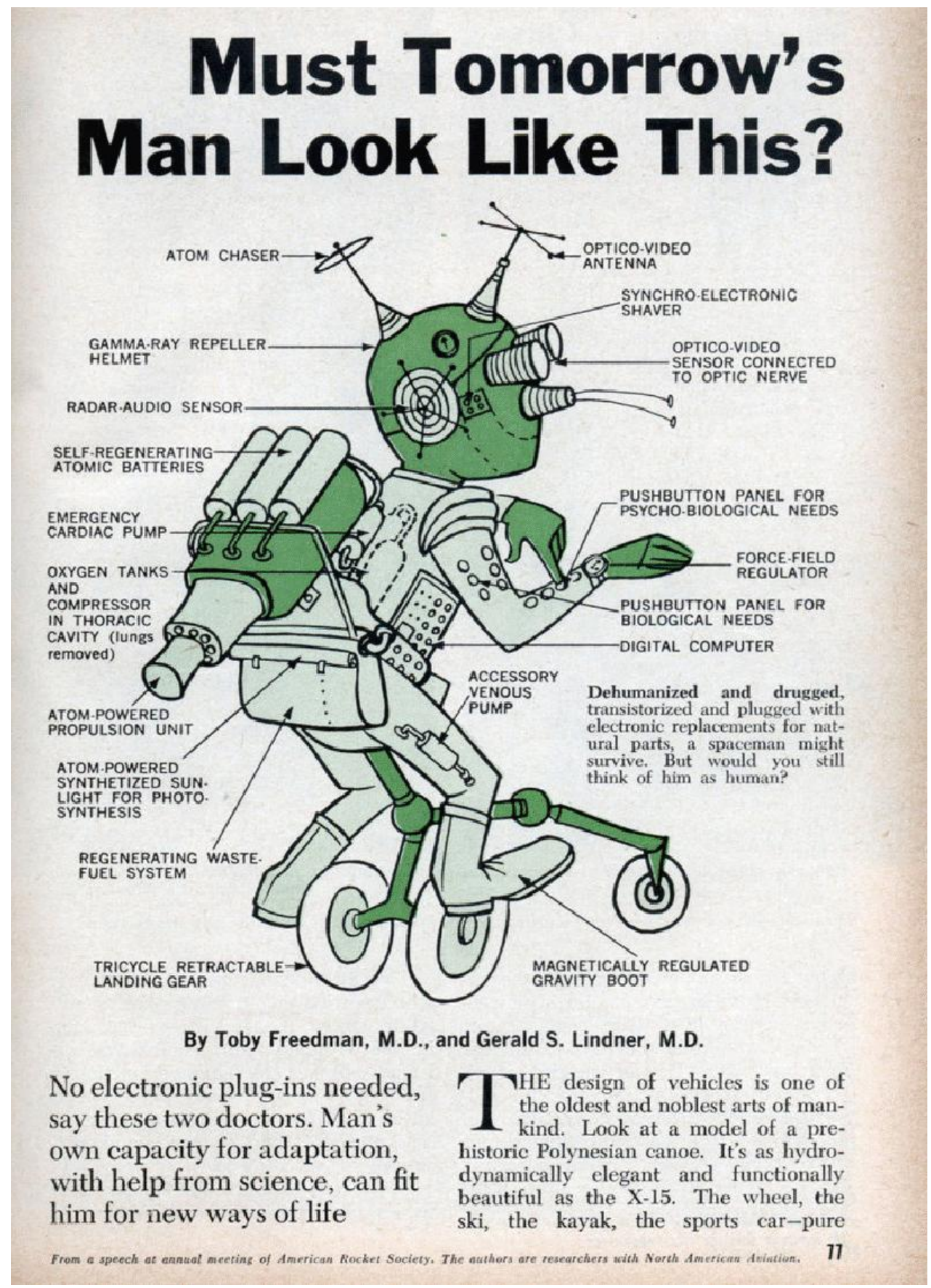

Figure 3.Popular Science Magazine [18]. 


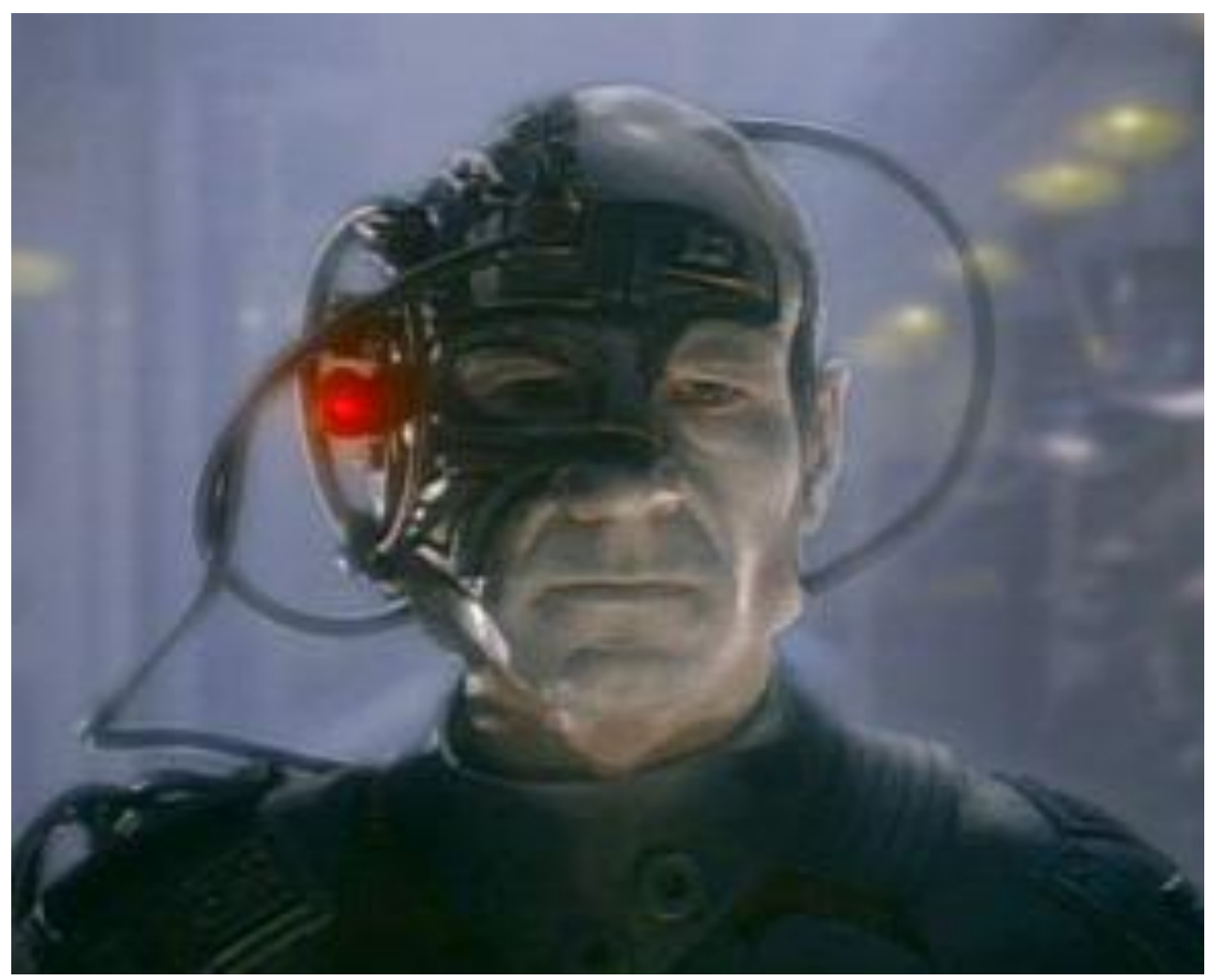

Figure 4. Locutus, Star Trek [23].

Due to the proximity with the body, the term cyborg is commonly associated with wearable computers, and science fiction has foretold the merging of man and machine for many years, but it is usually presented as a human with electronics emerging from his skin. For instance, one of the arguments against the early adoption of wearable computers is their cyborg look. If we take the vision of Mark Weiser (cited above) more seriously, we will no doubt recognize that our wearable technologies are nevertheless very 'distinguishable'. In this project, we propose interfaces "becoming" cyborgs but without having their stereo-typical visual aesthetics.

\subsection{Thesis Organization}

This document is organized in six sections:

- Chapter 1. Introduction. In this first chapter, an overview of this work was presented. Invisible Computing, Wearable Technologies and Cyborg Fashion expose the motivations of this thesis.

- Chapter 2. Related Work. This chapter provides the background of how technology was to be used as an interactive platform for other researchers and related work relevant to this study. 
- Chapter 3. Beauty Technology. This chapter defines Beauty Technology. It presents the muscle movements that were used as inputs in the creation of Beauty Technology prototypes. Thus, the structure of this chapter is based on muscle movements that were used to show the feasibility of this technology, as it is shown in Figure 5. Our prototypes have been developed based on this taxonomy on Facial Expression and Arm/hand movement.

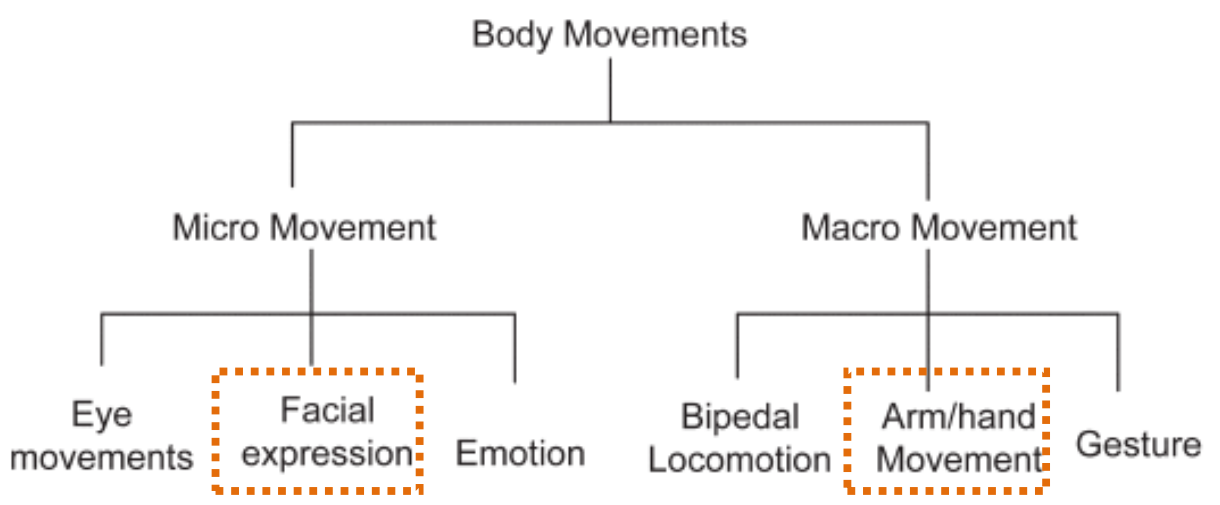

Figure 5. Taxonomy of Body Movements [24].

- Chapter 4. Facial Expression. This chapter explains the design, technology and prototyping process for creating Conductive Makeup and FX e-makeup. Applications of this technology are presented.

- Chapter 5. Arm/hand movement. Beauty Tech Nails are a Beauty Technology prototype used to sense independent finger recognition. Applications that show the feasibility of this prototype are presented.

- Chapter 6 Conclusions and Future Work. Finally, this chapter draws conclusions and explains key contributions of the research. Publications, demonstrations, exhibitions and media coverage of Beauty Technology are listed. 


\section{2 Related Work}

The human body is becoming an important topic in the field of humancomputer interaction due to the proximity of wearables to the body and the aim of processing user's data in everyday objects. In this chapter, we review the aspects of the human body that could be sensed by wearable computers. Wearable applications are shown as examples of the use of the body as an input device.

\subsection{The Human Body as an Interactive Platform}

Aristotle (384 BC - $322 \mathrm{BC}$ ) is credited with the traditional classification of the five sense organs: sight, smell, taste, touch, and hearing [25]. Our senses link us to the outside world. As far back as the 1760's, the philosopher Immanuel Kant proposed that our knowledge of the outside world depends on our modes of perception [26]. But even if our perception is immediately aware of changes in our environment, our attention to specific targets is limited to the brain's ability to process these stimuli sequentially. Reflexes react to all stimuli arriving simultaneously to our sensory environment. But there are lapses in awareness of seemingly obvious stimuli to temporary losses of attention and lapses that we are not aware of in the form of reflexes.

Bio data is not expected to predict all future behaviors but it is useful in personnel selection in that it can give an indication of probable future behaviors based on an individual's prior learning history [27]. Humanistic Intelligence proposed by Mann [1] describes a framework wherein the natural capabilities of our human body and mind interact in synergy with one another and wearable computers become an integral part of the feedback loop.

Humans use a wide variety of muscles for creating gestures. They range from simple actions of using the hand to point at objects to the more complex actions that express feelings and communicate with others. Muscles movements are a clear representation of a user's intent [8]. When we initiate a voluntary motor, the brain sends an electrochemical signal that traverses our nervous system through the spinal cord and eventually arrives at the motor neurons. They stimulate our muscles causing movement or force [28]. 
Electromyography (EMG) is a technique that is used for detecting muscular movements. In this technique, users must wear gel-based sensors firmly held in place with adhesives [24], [29]. Computing vision offers a possibility for handsfree interfaces to sense movements and gestures, and reproduce them in a 3D environment [30]. However, it presents some issues like occlusion and lighting that limit the opportunities for use [51]. By using wearables and computer vision techniques for tracking macro-movements, it is possible to interpret pose and motion in many applications. Most approaches use machine learning algorithms and classifiers based on graphical models for macro-movement recognition. Figure 6 shows the skeleton model often used in Kinect applications. It is a treegraph consisting of 20 nodes corresponding to certain key joints in the human body [32]. Usually a set of parameters such as joint locations, velocities and accelerations localize and track movements. For example, SixthSense [33] is a camera and projector mobile device that recognizes different objects in the environment and gestures made by the user's fingers and hands. Armura [34] is an on-body computer interface that tracks the location of the arms and hands, as well as recognizes their gestural state and provides graphical feedback onto the body.

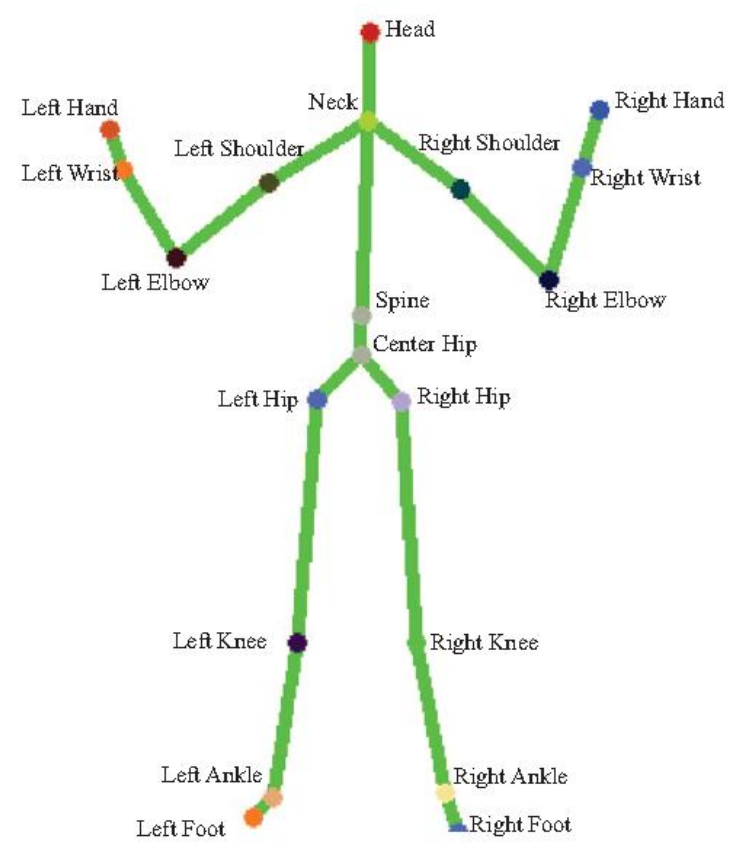

Figure 6. Skeleton model with 20 joints [32]. 


\subsection{Interfaces on Skin}

Wearable electrochemical sensors are a new sensing paradigm developed for healthcare [35]. Advances in this technology when integrated into clothing could be considered as non-invasive but they cannot easily be attached and adapted to the body for extracting data [36]. Temporary Transfer Tattoo [37] are electrodes that are printed directly on the epidermis realized by dispersing carbon fiber segments within the tattoo ink and have more than 12 hours of continuous wear without degradation. These electrodes could be designed in artistic tattoo patterns: a true integration with wearable computers and an attractive way of hiding sensors is expected.

Mc10 is proposing smart sensing stickers for medicine, therapy and healthcare in a bandage-like device [38]. They printed electronic mesh into a flexible and thin plastic that is malleable and adaptable to the human skin as a removable tattoo in order to obtain signals from the heart, muscle, body temperature and motion, signals from the brain, and even hydration levels. Figure 7 shows an example of this technology [39]. Mc10 stickers containing different sensors, wireless communication and a thin-film battery inside are expected, however, this technology is still in development and while the circuits are designed in an attractive shape they are still shown.

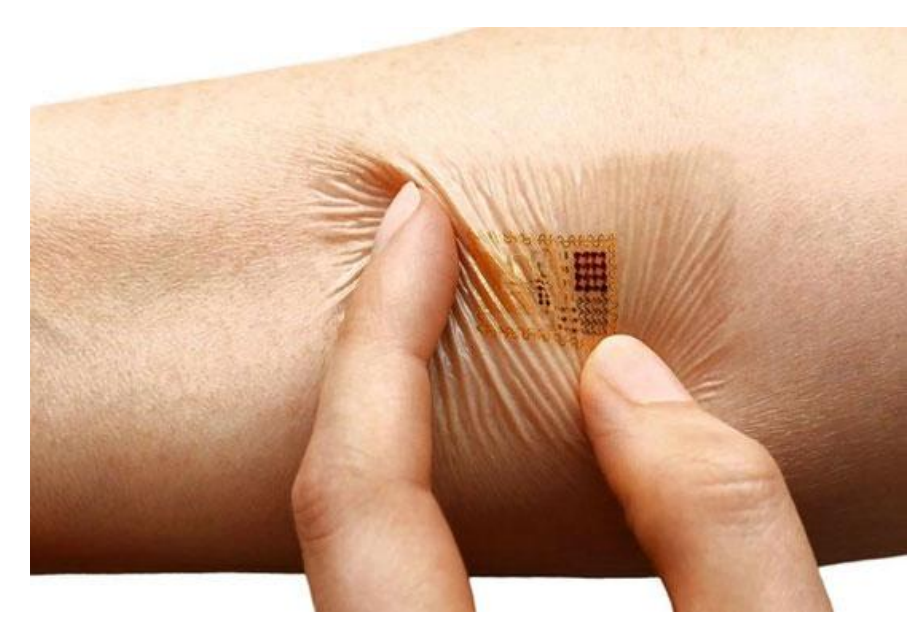

Figure 7. MC10 Inc.'s flexible electronic sensors are about the size of a postage stamp [17].

Even though the privacy and health issues are still evolving, wearers nevertheless seize opportunities to experiment with the sensation of being injected with tiny electronic devices - not just for health management, but also looking for new 
experiences and fashion, like tattoo implants that use the skin as a display [37] and chipping humans with RFID tag implants to track people's comings and goings $[40,41]$. In the Arts field, there are some efforts too, by including LEDs next to the eyes connected by thin wires they can simulate larger eyes [15] or act as eye shadow lights when the eyes are closed [42].

\subsection{Interfaces for Sensing Blinking}

The nature of the human visual system is such that high resolution is restricted to a small area, requiring the gaze to shift to each area of interest, indicating changes in visual attention and reflecting the cognitive state of the individual [43]. These eye movements have been studied in an effort to derive finer indicators of cognitive activity such as reading, searching and exploring. The human eye has been used as a hands free input device. For example, a system in which a user blinks in order to click and make left/right blinking combinations to completely control a system using the eyes.

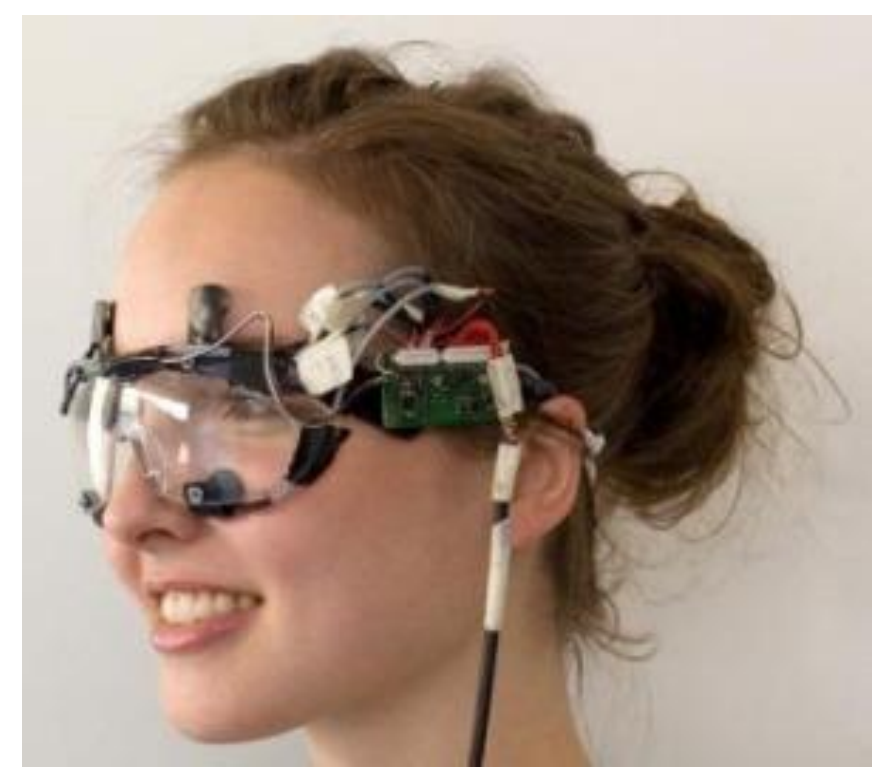

Figure 8. Goggles with electrodes for sensing blinking [47].

Blinking could be sensed by both vision and non-vision computational techniques. Non-vision techniques include electro-oculography (EOG) and high frequency transceivers. When humans initiate a voluntary action, the brain sends an electrochemical signal that traverses our nervous system through the spinal cord and eventually reaches the motor neurons. They stimulate specific muscles causing movement or force [44]. Being used to detect muscular movements, an EOG 
signal is based on electrical measurement of the potential difference between the cornea and the retina. The cornea-retinal potential creates an electrical field in the front of the head. Electrodes placed near the eyes detect changes in electricity. In this technique, users must wear gel-based sensors attached to their muscles with strong adhesives [45], [46]. Figure 8 shows a wearable device that consists of goggles coupled with electrodes integrated into the frame connected to a pocket-worn component that both records EOG signals and streams them to a remote device over Bluetooth. [47].

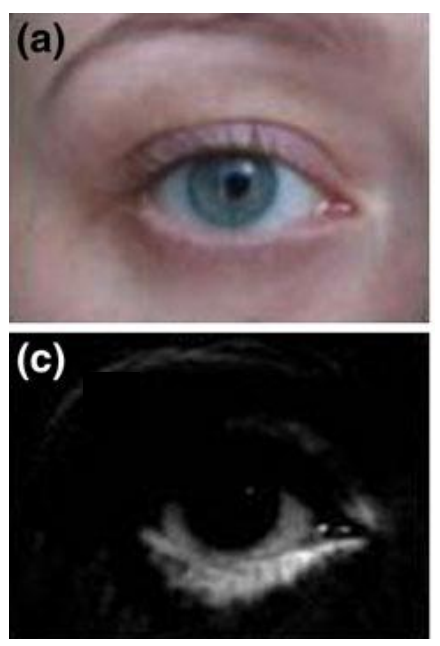

\section{(b)}

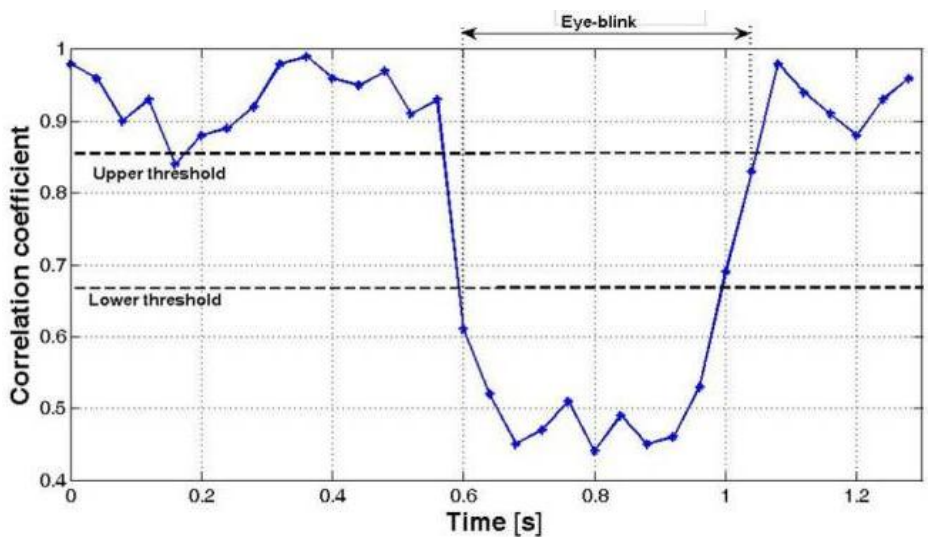

Figure 9. Blinking detection by means of difference images:

a) image of opened eye, b) correlation coefficient value in time during blinking, c) differentiate image. [51].

Computational vision methods for blinking detection are classified into two groups namely, active and passive. The active blinking detection technique requires special illumination to capture the retro-reflective property of the eye. The camera identifies a reflected beam on the pupil when the light source is focused on the focal axis of the camera. On the other hand, passive blinking detection methods do not use any additional light sources. Blinking is detected from the sequence of images within the visible spectrum in natural illumination conditions. They use different approaches for this purpose, such as template matching [48], skin color models [49], projection [50] and directional Circle Hough Transform [31]. Figure 9 shows a Blinking detection system [51]. Blinking is identified as the spike of waveforms as it is show in Figure 9b [51]. In this application, lower and upper thresholds are established for detecting eye closure. If the eye stays 
closed for a specific period of time, an eye blink is detected. Figure 9a and 9c shows blinking detection by means of differentiating images [51].

\subsection{Interfaces on Facial Muscles}

In past decades, significant effort has been made in developing techniques for sensing facial expressions [52]. A facial expression originates from the motion of the muscles beneath the skin of the face. Involuntary movements convey the emotional state of an individual to observers through non verbal communication.

Micro-movements involve facial muscle actions which are triggered by the nerve impulses generated by emotions. Maximally Discriminative Facial Movement Coding System (MAX) [53] and Facial Action Coding System (FACS) [54] are observational coding systems to identify micro-movements thought to be associated with emotion. All possible facial displays are coded in 44 action units that represent a set or an individual muscle movement [55]. Traditionally, FACS' measurements are done by experts' observation [54]. However, thanks to advances in technology, there are other techniques that support recognition of action units like Computational Vision techniques, which senses movements and gestures and reproduces them in a 3D environment [30].

For the purpose of this research we are interested in sensing voluntary movements. When humans initiate a voluntary action, the brain sends an electrochemical signal that traverses our nervous system through the spinal cord and eventually reaches the motor neurons. They stimulate specific muscles causing movement or force [54]. Non-vision techniques for identifying voluntary actions include Electromyogram (EMG) that is based on electrical measurement of the potential difference between two muscles. There are some known issues associated with using EMG [55] such as the placement of the leads on the face inhibits the movements of the subject, ambiguities in the measurements due to the proximity of the muscles and lack of specific places to attach the electrodes. Figure 10 a shows a head-mounted measurement device that senses the intensity of facial activity [E1]. The muscles responsible for raising the eyebrows, lowering the eyebrows, raising the mouth corners, and pulling down the mouth corners are measured simultaneously with a capacitive method and EMG. Figure 10b shows the artist Manabe using electric sensors to stimulate muscles in his face in synchronization with music [56]. Another example is a Tongue Computer Interface that was developed for patients with paralyzing injuries or medical conditions. 
Infrared optical sensors are embedded within a dental retainer in order to sense explicit tongue movements [57].
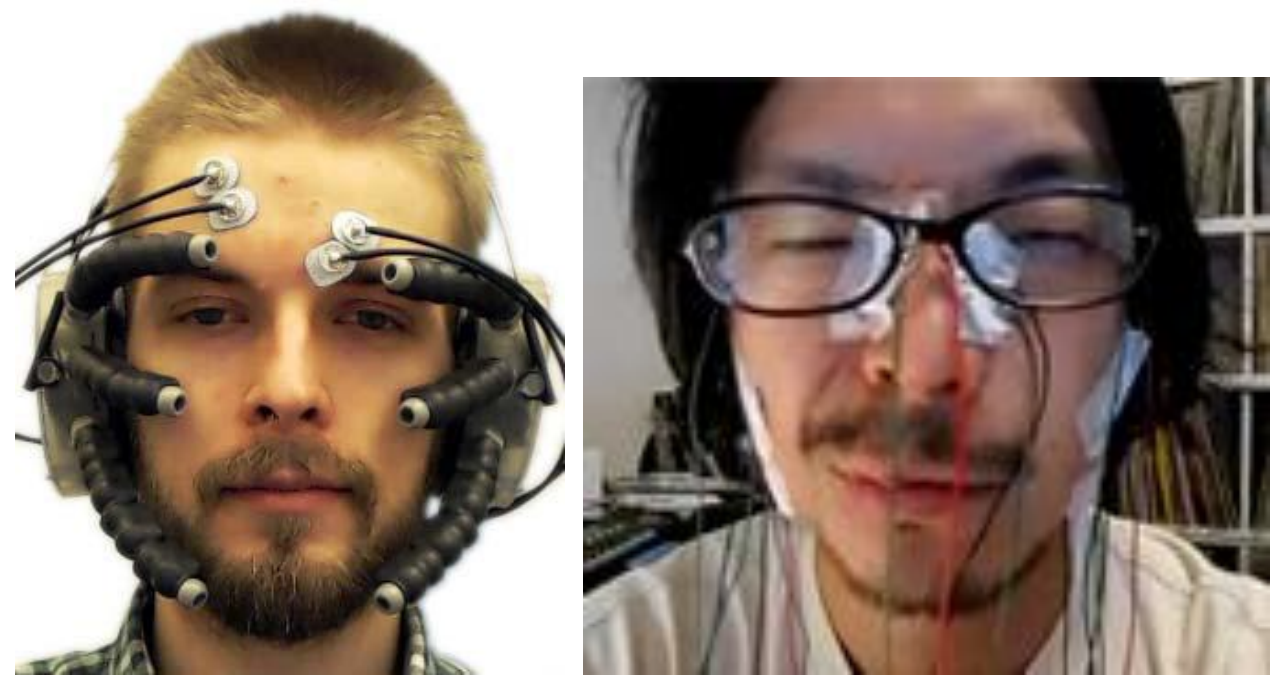

Figure 10. Facial Muscles Interfaces.

a) Measuring upper face movements with a Head-Mounted Measurement Device [56]. b) Music created by face muscle movements [57].

\subsection{Interfaces on Fingertips}

Although many projects presented finger gesture recognition through cameras and Microsoft Kinect, this work focuses its analysis on wearable computers that are always-available and mobile features. Fingertips are in direct contact with objects that humans interact with and finger muscles are finely controlled by our motor system. Thus, devices mounted on nails and fingers have been developed for mobile and ubiquitous interactions like nail displays, rings with embedded electronics and magnetic sensors bracelets.

Nail mounted displays are one example of wearable devices that augment reality by providing a visual feedback to the wearer [58]. Figure 11 shows "NailDisplay" [59], an OLED display coupled with sensors atop a fingernail. When the finger is placed on the smartphone screen, the nail display augments its visualization. It also has sensors for identifying pressing and shaking motions. "Fingernail Displays" [60] envisions the use of a nail polish that automatically configures itself to an active matrix color display.

Finger-worn devices could embed several sensors for gesture recognition. "FingerRing "[61] places rings coupled with accelerometers on every finger to sense different chord gestures in order to be used as a wearable keyboard. Fig- 
ure 12 shows "Pingu" [62], a ring that detects motion by using accelerometers and gyroscopes, and orientation by using magnetometers.

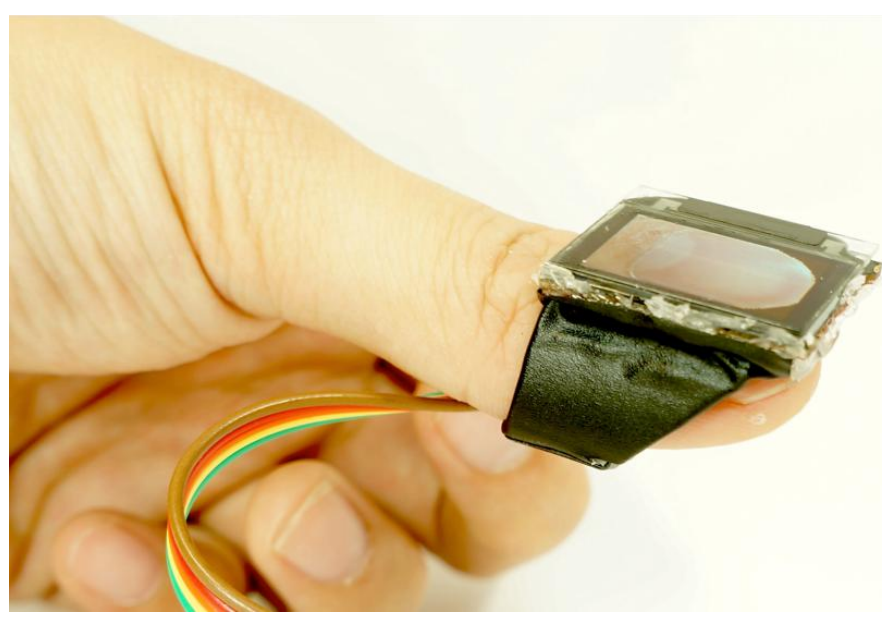

Figure 11. NailDisplay, OLED display on the fingernail [59].

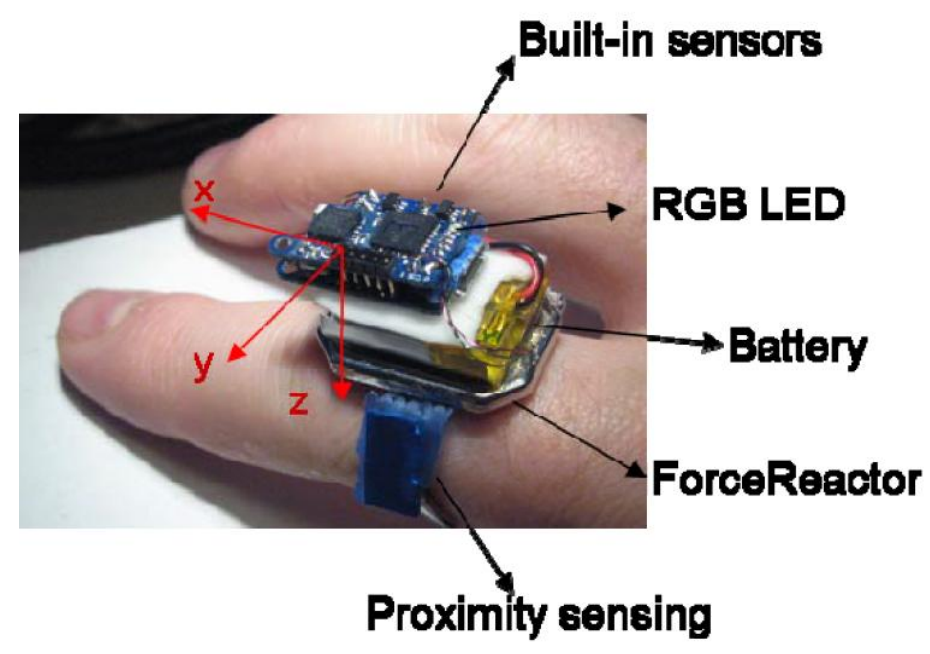

Figure 12. Pingu, fingering for gesture recognition [62].

Another technique for recognizing gestures is by tracking hand motion. An object that has a magnetic sensor could recognize a magnet located on any finger. "Neya" [63] is a tracking bracelet that detects the 1D input of a strong magnetic ring and communicates wirelessly with other devices. Likewise, "Abracadabra" [64] uses a magnet on the fingertip to control a wristwatch (Figure 13). 


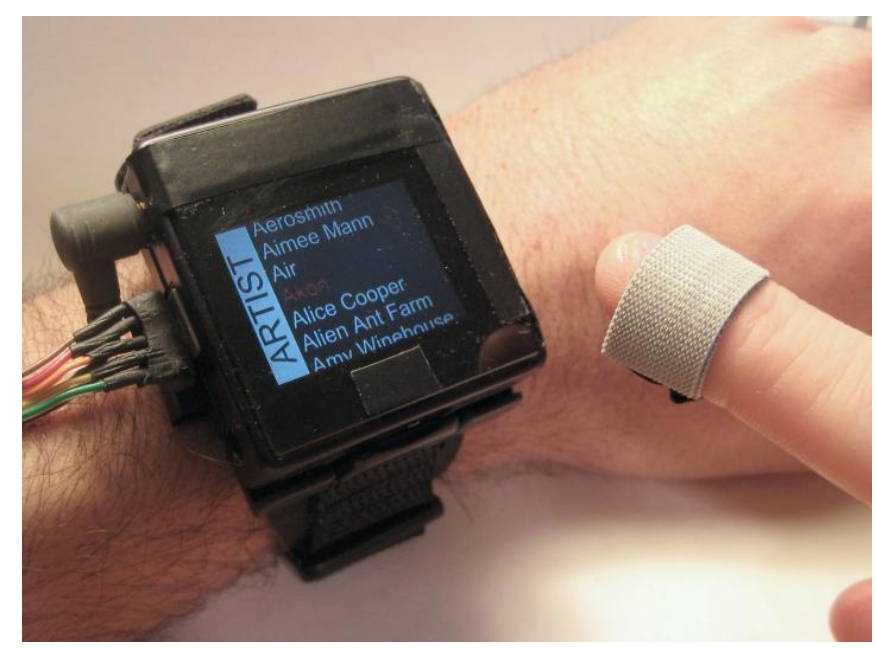

Figure 13. Abracadabra, wristwatch controlled by magnets on fingertips [64].

Hinckley [65] identifies these three characteristics of several input devices. Several touch input devices could recognize user's fingers that are in contact with the object. For example, a Microsoft Surface visualizes enough of the hand in proximity to the display that it is possible to determinate which finger is making contact with the device [66]. Input devices could differentiate between users. DiamondTouch [67] identifies the touch of one user from another by a surface that generates location dependent electric fields, which are coupled by capacity through the users to receivers installed in the work environment. Although it raises security issues, fingerprints are commonly being used to identify users. Computer vision techniques are also being used for user identification and to distinguish finger differentiation [65]. 


\section{3 \\ Beauty Technology}

Wearables are more personal than traditional smart objects because they are part of the owner's physical presence: "they are not only part of what you wear but also part of who you are [68]". In this chapter, we define Beauty Technology for creating an Interactive Computing Platform on the body surface. It exposes a classification of Body Technologies by its position in the body and the taxonomy of movements used for creating this Muscle Based Interface.

\subsection{On Body Technologies}

Given the Wearables revolution, the human body becomes a design standpoint. Thus, different body features such as localization, form, texture and temperature must be considered in the creation of wearables. On Body Technologies are electronic devices that can be portable. Figure 14 shows our classification of On Body Technologies, which focus on the context of Beauty Technology applications. In this way, Wearable Computers are on the body, technology can be inside the body such as implants or carried next to the body such as Mobile Computers. The main difference between Mobile Computers and Wearables is that the former often requires your full attention and both hands [68]. Instead of embedding electronics into a wearable, that is a familiar object for humans, they are electronics created for a specific purpose and with a specific shape. Wearable Computers can be placed not just in clothes and accessories, but also on the top of the body's surface.

We propose Beauty Technology as a Wearable Computing field that fits this category, placing technology on the skin, nails and hair. Skin and its appendages (i.e. hair and nails) are regenerative organs that play a crucial role in human beings such as: a protective barrier, a sensory input from the environment, a heat and moisture regulator and a part of the immune system [69]. Moreover, they have being manipulated with tattoos and beauty products as since the earliest days in the human race [70]. 
Figure 15 shows Pearson's visions [11] defining multiple layers of technology into/onto the skin and communication possibilities through these layers. The Wearable layer sits on the body like everyday gadgets such as a watch. The transfer layer sits just on the skins surface (not in it). In this layer, technologies are stuck onto the skin surface but they could be easily removed. The detachable layer places fully removable devices that are only worn on a temporary basis, but are in interaction with the layers below. The tattoo layer permanently prints technology into the lower layers of the skin. This work lists technologies that are not necessarily in the real world yet, it offers researchers the inspiration to create them.

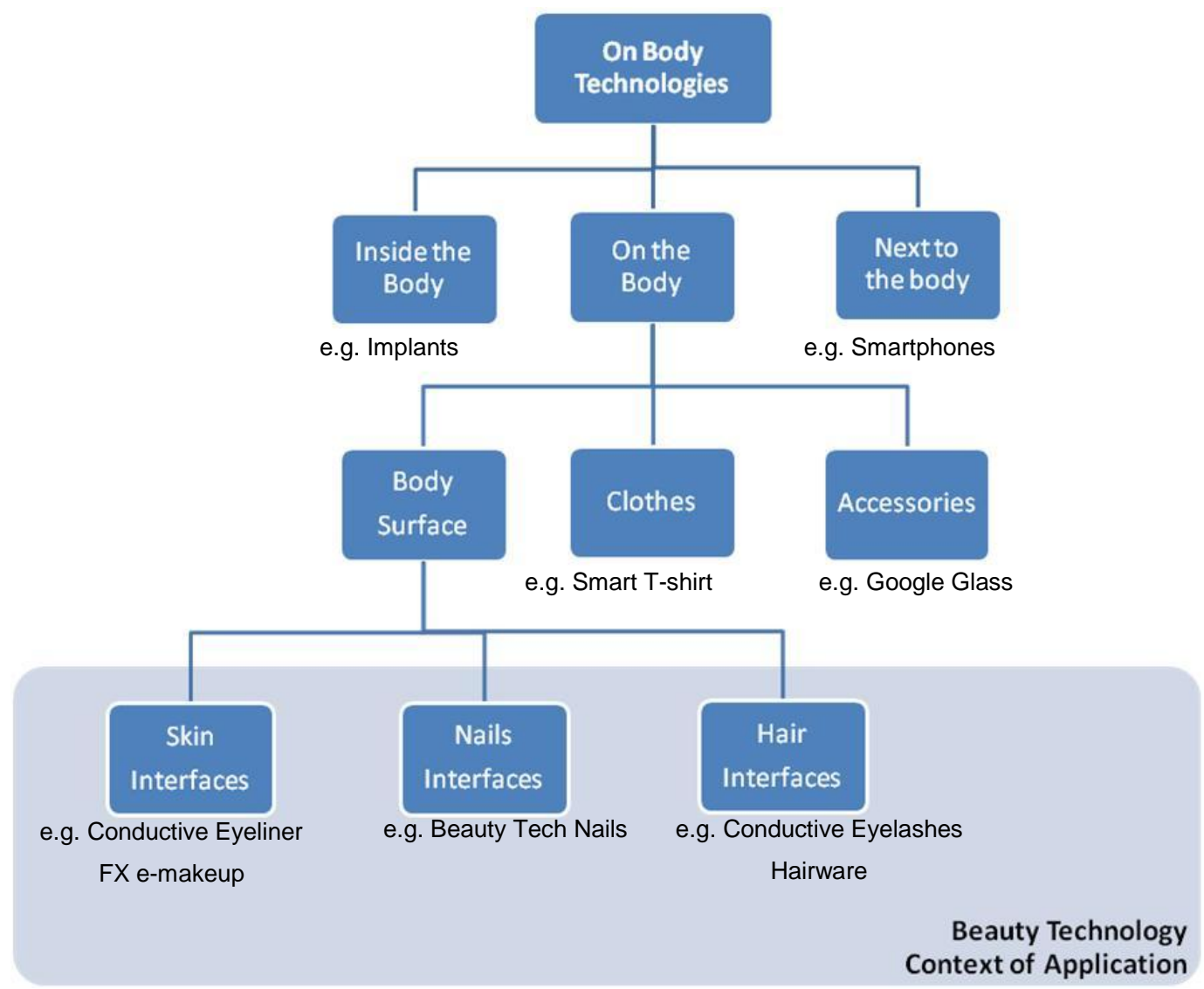

Figure 14. Body Technologies by their locality. 


\section{Active skin system overview}

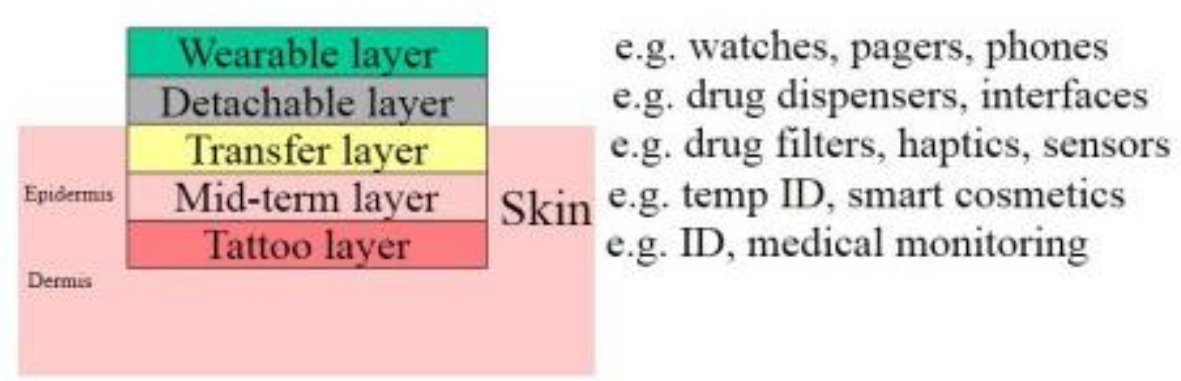

Upper layers of the skin, such as the Stratum corneum, contains no nerve endings so is useful for components too large to be injected into the lower layers of the epidermis or the dermis. The dermis contains nerve endings, hair follicles etc

Figure 15. Multilayer classification of devices on the Skin [11].

\subsection{Muscle Based Interfaces}

Human Computer Interaction can use movements as explicit and implicit inputs. A muscle-based interface is used in this project as the interactive strategy for sensing movements as inputs. Figure 16 shows the taxonomy of Body Movements [24]. It classifies movements into Micro and Macro Movements. Initial Beauty Technology prototypes studied Facial expression Micro movements such as blinking and facial movements, and Arm/hand Macro movements such as finger movement.

Non-verbal human interaction, facial expressions and body gestures communicate emotional content [71]. Thus, facial expression recognition has attracted the interest of the artificial intelligence and computer vision communities mainly for identification of human emotions [72].

Fine motor coordinates are small muscle movements which occur in body parts such as the fingers, usually in coordination with the eyes. In relation to motor skills of hands and fingers, the term dexterity is commonly used. The independent control of finger movements is a key feature of the dexterous use of the hand. A superior independence of finger movements in humans over non-human primates indicates the development of this motor function in parallel with the evolution of an ability to manipulate various tools [73]. 


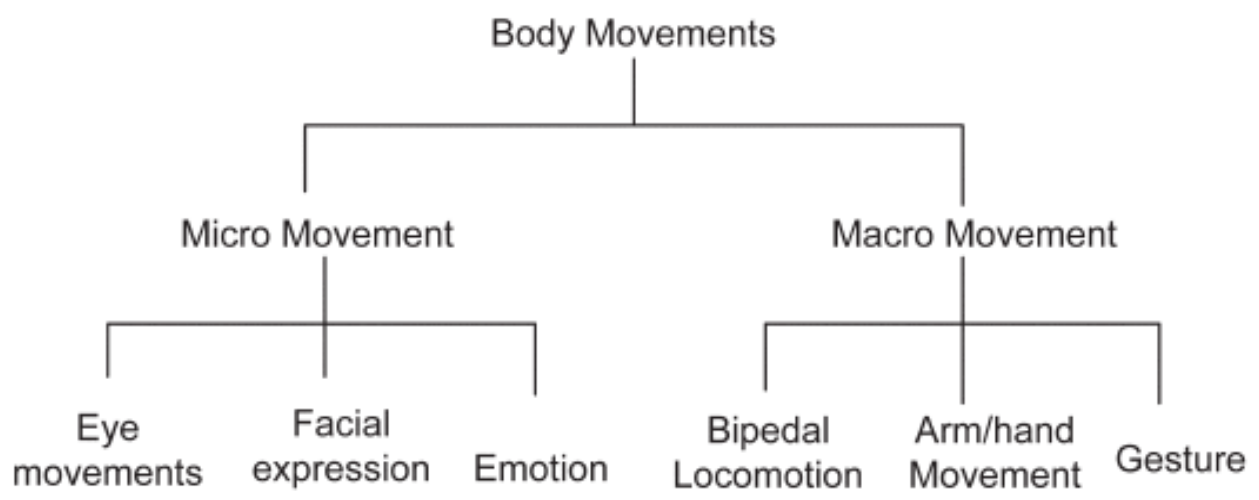

Figure 16. Taxonomy of Body Movements [24].

\subsection{Beauty Technology as an Interactive Computing Platform}

This section introduces the term 'Beauty Technology' as an emerging field in Wearable Computers. We propose the use of products on the skin surface that hide electronics, are easy to attach and remove, are ergonomic to the human body and highlight the wearer's personality.

'Beauty technology' are wearable devices that act as removable and hidden electronics attached to body surfaces enabling wearers to interact with the digital world without interfering in everyday activities. In particular, the term includes electronics embedded into beauty products. Common beauty products are easy to attach and remove, are designed ergonomically for human bodies, and are widely available and their main goal is to enhance physical appearance. This work adapted beauty products and embedded electronics to increase the possibilities for wearers to interact with the world.

False eyelashes, false nails, conductive makeup and FX e-makeup are some examples of beauty prototypes that were adapted with electronic components in order to create actuators that communicate with the wearer, other objects and the virtual world. For example, instead of using a staff card for opening the office door, a special finger movement with RFID TechNails could identify employees and grant them access.

The first technologies developed for Beauty Technology were: conductive makeup for connecting sensors and actuators on the facial skin; black false eyelashes that were chemically metalized to act as switches that communicate blinking; and false nails (plastic, acrylic and gel) that hide components like RFID glass capsule tags, magnets and conductive materials. 
Applications were developed as examples of the use of the Beauty Technology. Blinklifier and Arcana use false eyelashes and conductive eyeliner for communicating blinking and amplifying it through an artistic head dress that has a microprocessor and an LED matrix that produces changes in light patterns, and in the case of Arcana, through music and images visualizations are created depending on the wearer's blinking. Superhero also uses false eyelashes and conductive eyeliner to communicate the wearer's blinking and change the environment in ways such as shifting displayed images and even, levitating an object. Abrete Sesamo is a Beauty Technology project that unlocks a door when a secret combination of finger movements is read from the wearer's nails, which are embedded with RFID tags. AquaDjing is a DJ music controller device that is operated through touching water with RFID nails. 


\section{4 \\ Facial Expression}

This chapter describes the materials and the prototyping process used in the making of interfaces that react to the facial expressions. Conductive Makeup and FX e-makeup are the Beauty Technology prototypes.

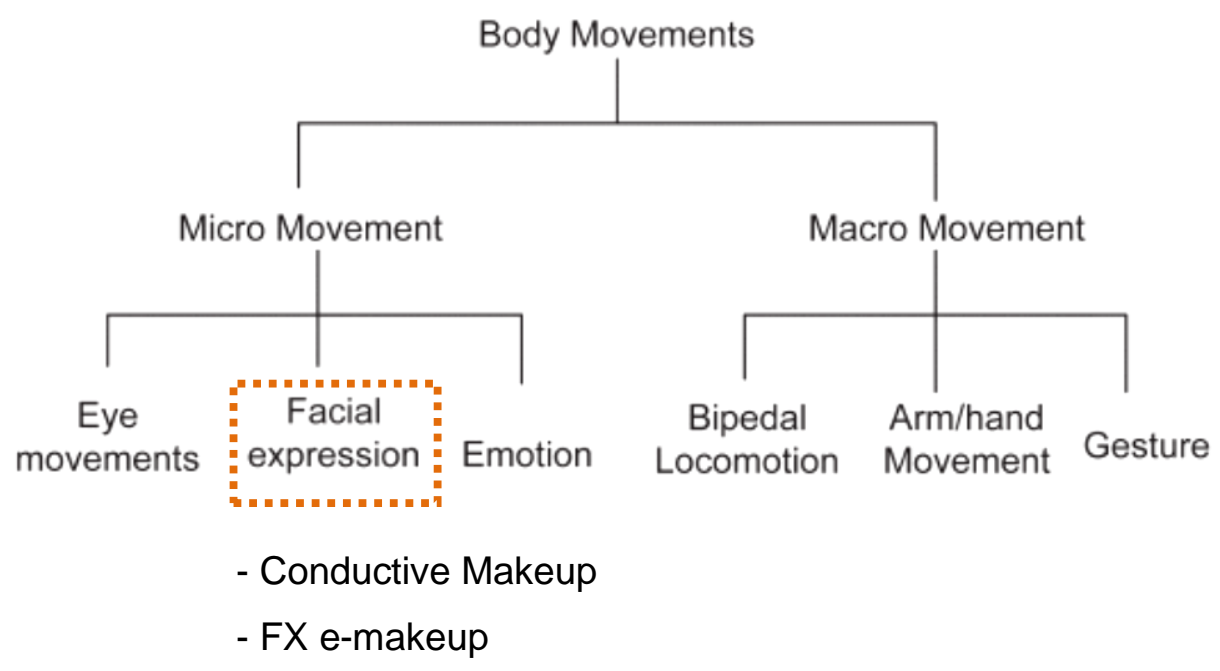

Figure 17. Adapted from "Taxonomy of Body Movements" [24].

\subsection{Conductive Makeup}

Beauty products seem to be culturally and fashionably accepted for enhancing or altering the user appearance and are considered by many as essential daily products. Beauty Technology focus' on everyday bodily worn objects like beauty products that can hide technology to create muscle based interfaces that are not readily visible. This project describes the materials and the process used to prototype an eye-liner based conductive makeup and conductive fake eyelashes used for detecting voluntary blinking. Based on this technology, this section presents the projects Blinklifier, Superhero and Arcana as proof of concept for a muscle based interface object controller. Current work adapted to the needs of quadriplegic, substitutes a latex based conductive makeup for the eyeliner.

As the eyes are a rich source of information for gathering context in our everyday lives, $\mathrm{HCl}$ researchers have investigated the potential of eye movement 
as a form of input. Six extrinsic muscles allow for vertical, horizontal and rotational movements of the eyeball. BlinkBot [74] is a hands free input interface that control and command a robot. It uses gaze and blinking as input instructions to direct a robot to move an object from one location to another.

\section{Blinking Interaction}

The tears are moisturizer that clean the eye and remove foreign substances. Certain external factors or conditions affect the natural process of blinking [75]. Blinking is classified as endogenous, reflex or voluntary blinking [76]. The endogenous one is identified as a cortically controlled response event, distinguishable from other blinks by the absence of an identifiable eliciting stimulus. It is the body's way of spreading tears and other moisture across the eye. The reflex of blinking is a protective response that occurs as stimuli to avoid potential injuries to the organism. Thus, it responses when something invades the eye, like air puffs or dust, and is also part of the fright reaction to loud noises. The voluntary blinking takes place in response to an identifiable stimulus, either selfinitiated or at the request of a researcher [75]. Microsleep, being regarded as a non-blink closure, is observed in sleep-deprived or otherwise fatigued individuals.

Blinking takes place approximately 10 to 15 times per minute. The normal duration of blinking is in between $150-250 \mathrm{~ms}$ and the longest closure period during blinking is estimated to be $270-300 \mathrm{~ms}$ [77]. To use blinking as a means of triggering, we defined a voluntary blinking closure duration that should fall between a pre-set minimal and maximal duration. Based on this data, we estimate that the range in Beauty Technology applications is between $0.5 \mathrm{~s}$ to $2 \mathrm{~s}$. Therefore, any eye closure which satisfies this criterion is regarded as a blinking trigger. Voluntary long blinking triggers smart objects, while involuntary short blinking are simply ignored. Also a combination of blinking could be identified as one or a sequence of instructions for interaction.

The eyeliner must be precisely applied on the eyelids in a way that the upper and lower eyelashes only make contact when the eye is closed. They connect the conductive fake eyelashes to the wearable. The conductive eyelashes work like a switch which is off when the eye is open and on when the eye is totally closed. These digital signs are processed by a microcontroller hidden into a wearable like a wig or headband.

Conductive Makeup applications make use of blinking to interact with other devices and their own user. Figure 18 shows a drawing of a user wearing the conductive eyeliner and conductive fake eyelashes to communicate with other 
devices. For example, when the user closes her left eye, a digital sign is send to the radio network. The circuit that includes the radio module and the connections to the eyelashes are hidden inside the wearable. Other radio modules could be used to interact with a computer, a smart object or another wearable.

\subsubsection{Conductive Makeup}

Common beauty products are easy to attach and remove, are designed ergonomically for human bodies, and are widely available and their main goal is to enhance physical appearance. This work adapted beauty products and embedded electronics to augment the possibilities for wearers to interact with the world. In order to avoid using any electronic device on the wearer's face, skin conductive material was applied as black eyeliner to connect conductive false eyelashes to the wearable device. This eyeliner is a conductive tape that is cut in a shape of an upper or lower eyelid at the beginning and a slight line at the end. A black paint covers the silver color and gives a black eyeliner look. These eyeliners are placed in parallel with human skin glue that sticks the eyeliner in position and isolates the conductivity from the skin.
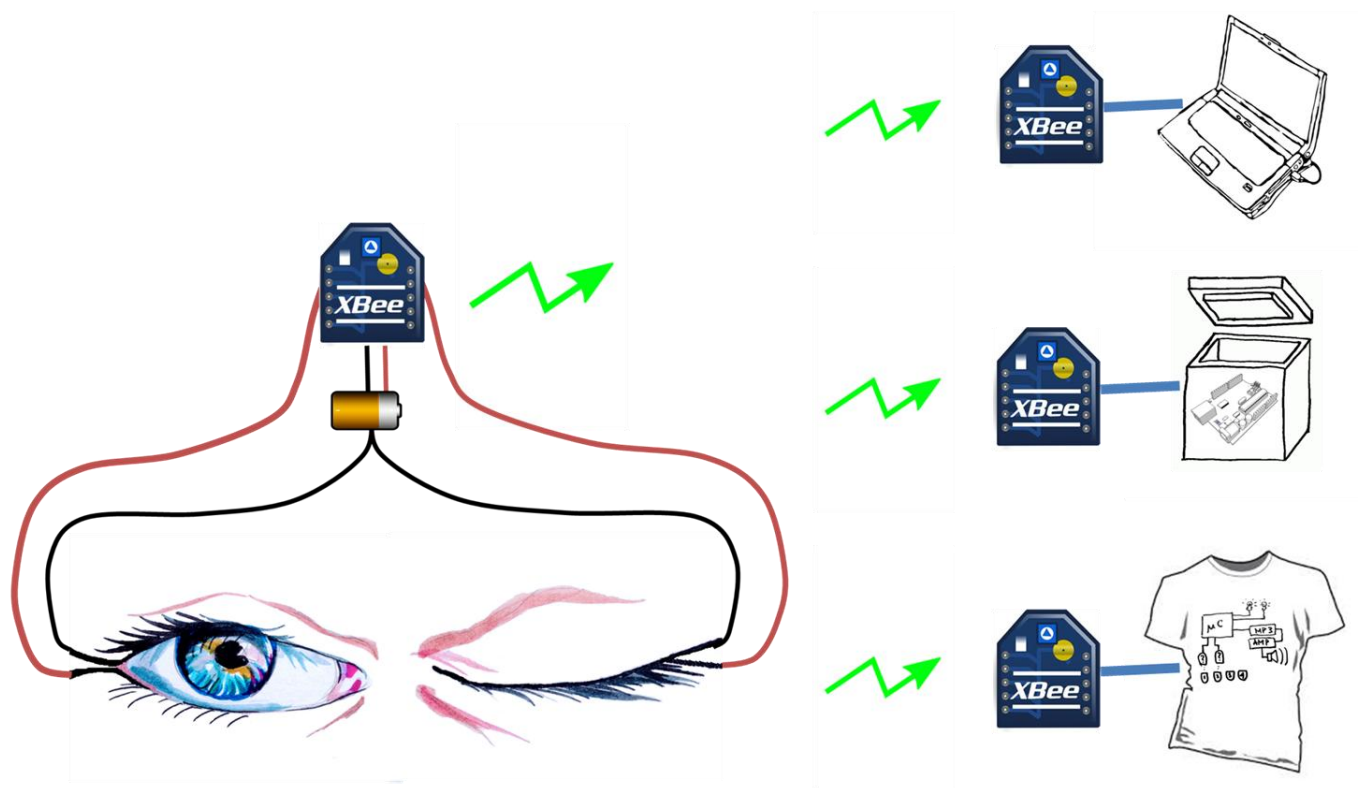

Figure 18. Conductive Makeup blinking interface.

The eyelashes are chemically metalized in order to mimic the natural black color of the eyelashes. The chemical process was carried out in two phases: Ac- 
tivation and Electrolysis. During the first phase, the false eyelashes, being plastic non-conducting surfaces, require some kind of activation to enable them to be used in an electrochemical process. The first activate was made using Hydrogen and Tin Chloride and then a silver nitrate solution was added in the second activate, setting up the eyelashes as catalysts of electron transfer reactions and ready for metalizing. The electrolysis phase deposited a layer of nickel on our active eyelashes to plate them. It made use of copper for making the eyelashes electrically conductive and black nickel for the natural black effect of the eyelashes. Figure 19 shows one of the phases of the electrochemical process. Table 1 shows the formulations and time needed for creating Black Metalized Fake Eyelashes.
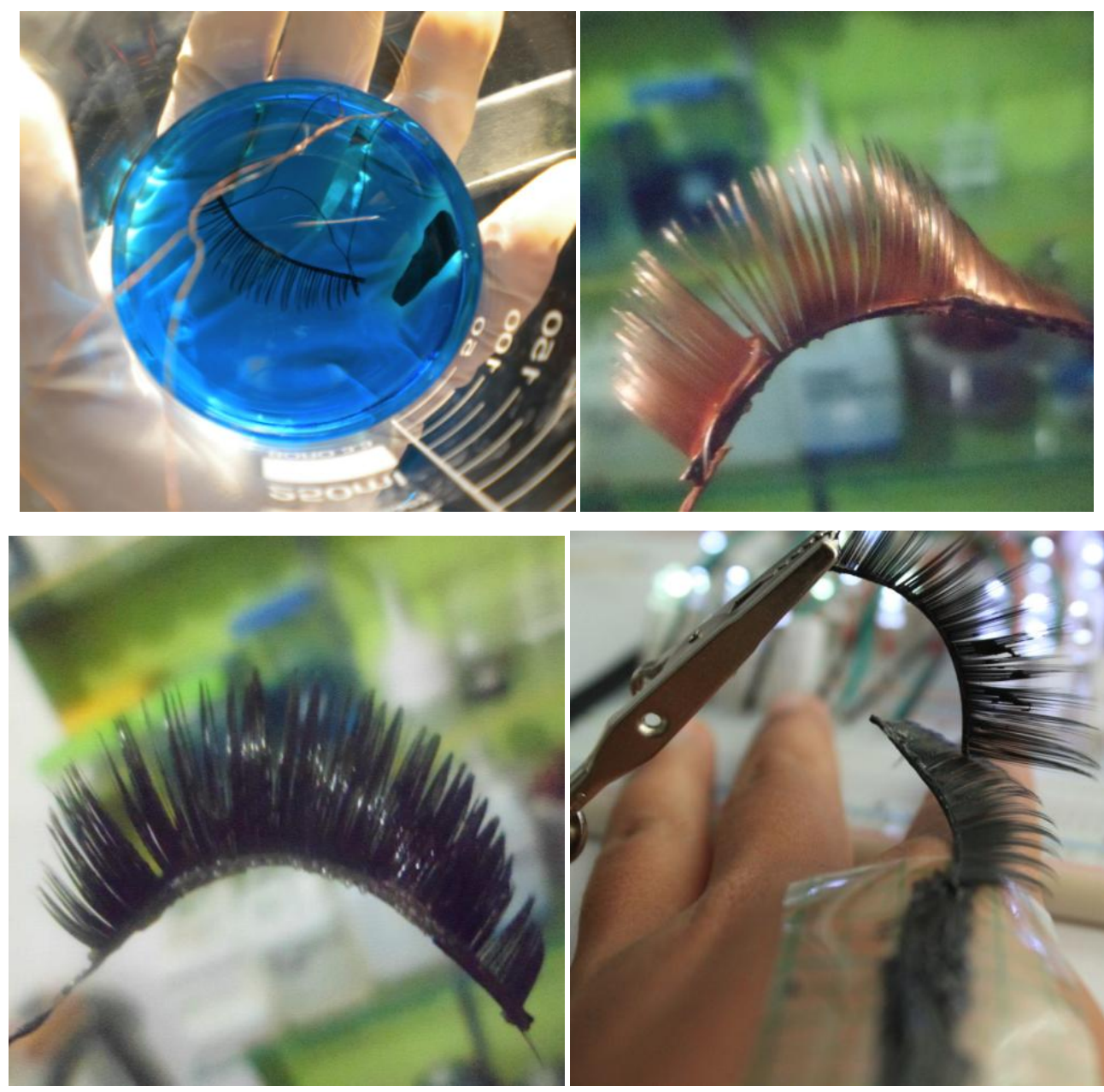

Figure 19. Metalizing black fake eyelashes. 
Table 1. Black Metalized Fake Eyelashes Electrochemical Process

\begin{tabular}{|c|c|c|c|c|}
\hline & & Formulation & Temp & Time \\
\hline \multirow{3}{*}{ Activation 1} & 1 & Liter of solution & \multirow{3}{*}{$21^{\circ} \mathrm{C}$} & \multirow{3}{*}{$5 \mathrm{~min}$} \\
\hline & 10 & grams of $\mathrm{SnCl} 2$ & & \\
\hline & 40 & $\mathrm{ml}$ of $\mathrm{HCl}$ & & \\
\hline \multirow{3}{*}{ Activation 2} & 1 & Liter of solution & \multirow{3}{*}{$21^{\circ} \mathrm{C}$} & \multirow{3}{*}{$5 \mathrm{~min}$} \\
\hline & 2 & grams of $\mathrm{AgNO} 3$ & & \\
\hline & 10 & milliliters of $\mathrm{NH} 3$ & & \\
\hline \multirow{5}{*}{ Copper Electroless } & 1 & Liter of solution & \multirow{5}{*}{$40^{\circ} \mathrm{C}$} & \multirow{5}{*}{$10 \mathrm{~min}$} \\
\hline & 14 & grams of CuSO4 & & \\
\hline & 30 & $\begin{array}{l}\text { grams of potassium sodium } \\
\text { tartrate }\end{array}$ & & \\
\hline & 10 & grams of $\mathrm{NaOH}$ & & \\
\hline & 40 & milliliters of Formaldehyde & & \\
\hline \multirow{7}{*}{ Copper Acid } & 1 & Liter of solution & \multirow{7}{*}{$21^{\circ} \mathrm{C}$} & \multirow{7}{*}{$10 \mathrm{~min}$} \\
\hline & 220 & $\begin{array}{l}\text { grams of copper sulphate } \\
\text { pent hydrate }\end{array}$ & & \\
\hline & 34 & milliliters of Sulphuric acid & & \\
\hline & 10 & $\begin{array}{l}\text { milliliters of Solution } \\
\text { Cupracid }\end{array}$ & & \\
\hline & 0.5 & $\begin{array}{l}\text { milliliters Cupracid Bright- } \\
\text { ener } 210 \text { Part } A\end{array}$ & & \\
\hline & 0.5 & $\begin{array}{l}\text { milliliters Cupracid Bright- } \\
\text { ener } 210 \text { Part } B\end{array}$ & & \\
\hline & 0.12 & grams sodium chloride & & \\
\hline \multirow{3}{*}{ Black Nickel } & 1 & Liter of solution & \multirow{3}{*}{$21^{\circ} \mathrm{C}$} & \multirow{3}{*}{$10 \mathrm{~min}$} \\
\hline & 120 & grams of Nickel Sulphate & & \\
\hline & 40 & grams of Nickel Chloride & & \\
\hline
\end{tabular}

\subsubsection{Conductive Makeup Applications: Electronic Divas}

Technologies for sensing information in personal spaces like blinking, pulse rates and respiration monitoring have advanced in recent years. In parallel technologies for communicating with smart spaces, smart objects, wearable devices, virtual worlds and social networks have also experienced a lot of enhancements 
in recent years. These technologies empower human capabilities and we foresee the use of wearable computers becoming a key component for interaction. With this evolutionary technology and our aim of hiding embedded electronics in everyday life objects, we put forward 'Electronic Divas': individuals empowered with 'Beauty Technology' based on Conductive Makeup. When they blink, objects levitate and sound tracks change. By wearing Beauty Technology products they amplify their capabilities, sense the world and highlight their personalities.

Arcana, Blinklifier and Superhero incarnate our 'Electronic Divas' in several performances and art exhibitions. Specific tasks were associated with winking the left and the right eyes, and closing both eyes. These gestures trigger actuators on the wearable and on other wireless devices.

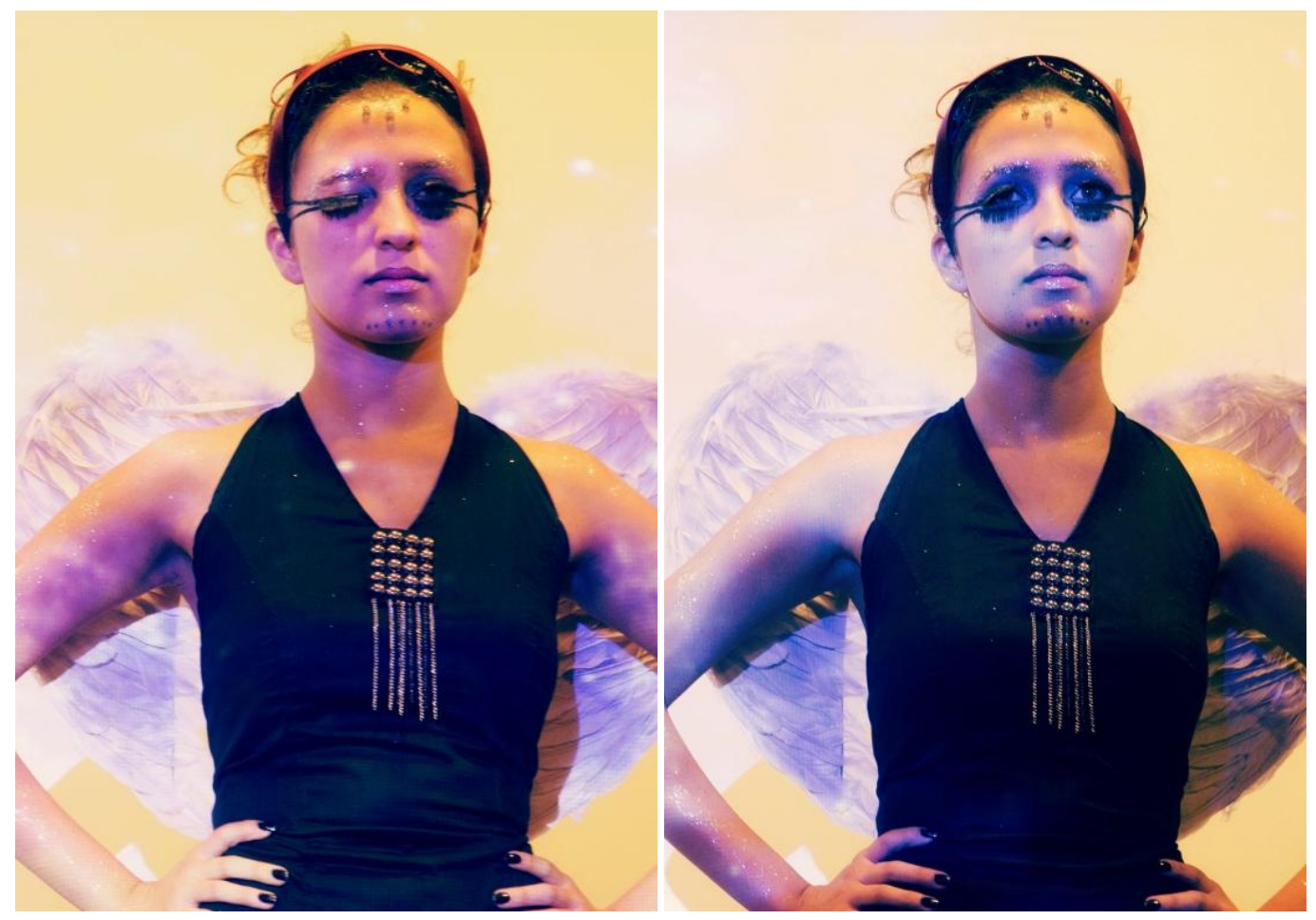

Figure 20. Arcana performance with conductive makeup.

The Blinklifier project began with the collaboration of three artists: a Japanese painter, a Chinese fashion designer and an Australian artist where a Japanese-inspired painting was turned into a fashionable dress and a matching head dress. By embedding technology into this head dress, a new collaboration between art and technology fostered the creation of Blinklifier. By responding to specific eye movement patterns, it communicates emotions by presenting noticeable, exaggerated visual compositions. It uses 72 LEDs to create blinking pat- 
terns on the head dress. Different light patterns show up when the wearer blinks with her left, right, opens and closes her eyes. The Blinklifier piece was shown in several exhibitions [82, 83, 84, 85, 86].

Arcana is another collaboration project with a makeup artist and an actress. Arcana is a futuristic angel that through blinking creates a different world around her, by changing musical tracks and images. Her eyes, using the conductive makeup are connected to a head band that hides a radio module for communicating when her eyes are closed as digital signs. Another radio module is connected to a computer that identifies the blinking in the range criteria and activates specific music and changes the visual images. This performance took place in an auditorium showing the projected images displayed on the actress [38]. Figure 20 shows Arcana when she blinks her right eye.

TEI 2013 Design Challenge [88] students were charged with the task of celebrating TEI creativity with a game or performance. Our Superhero project made use of the aforementioned conductive makeup and black false eyelashes, making it possible for the wearer to levitate objects through blinking. Eyelashes worked like switches that were connected to a circuit sending signals via a radio module to a nearby Superhero Handbag that housed the radio receiver. Accordingly, animated images were displayed (POW, BAM, ZAP) or infrared commands decoded from a remote controller's protocol and reproduced in order to make an object fly. Figure 21 shows the Superhero levitating an object by blinking the right eye.

\subsubsection{Lessons Learned}

Cutting aluminum foil into eyelash shapes created the first prototype for the eyelashes. The silver color conflicted with our goal of keeping the natural appearance of black eyelashes. They also lost their shape due to their own weight.

Another attempt to make conductive makeup was pursued using conductive ink [89]. This ink was used to draw a line on the eyes and it was also applied on the plastic eyelashes as mascara. Bare Conductive states that "though Bare Paint is a material that is safe to have around the body, it is not specifically approved for use on the skin" [89]. Moreover, due to the humidity of the eyes and skin, this ink could be dissipated in the eye. Another issue in the use of conductive ink was that it could lose conductivity if the dried ink split due to the flexibility of the skin and muscles movements. 


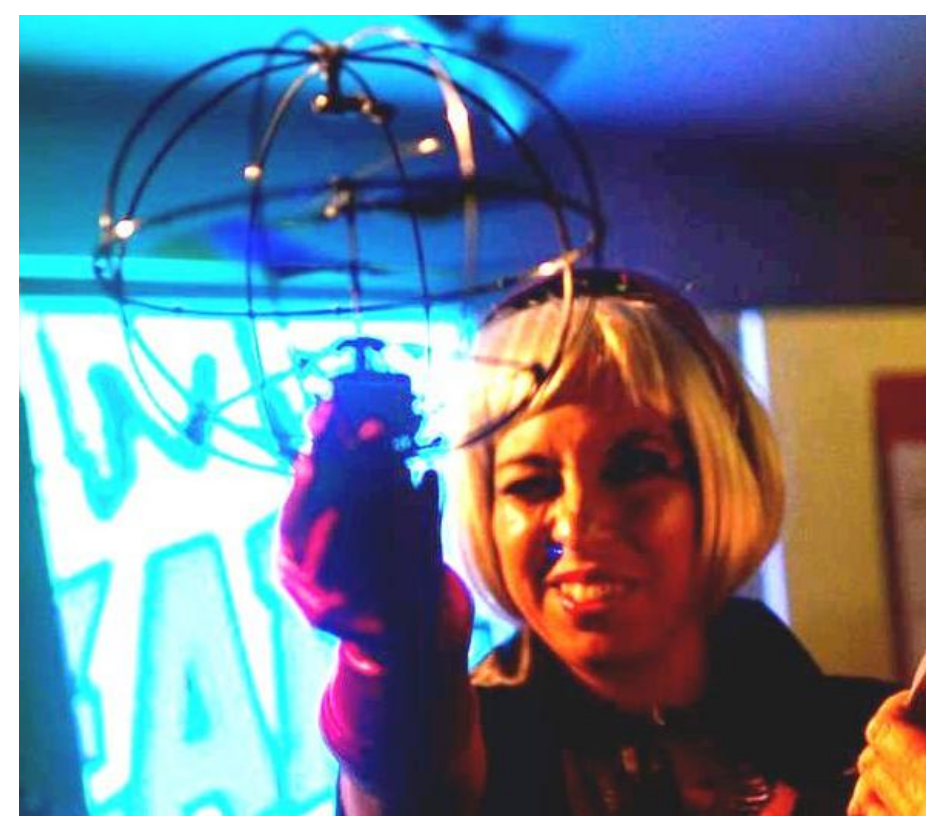

Figure 21. Superhero blinks for levitating objects.

While continuously sensing voluntary blinking, one issue that interfered with the signal, was facial expressions that involved the eye closure like smiling. A future work will include other sensors in different facial muscles for differentiating those movements.

The same conductive makeup (eyelashes and eyeliner) was worn eight times in testing and performances by the Electronic Divas: Blinklifier (twice), Superhero (five times) and Arcana (once). It required precise application on the skin with special glue. After wearing it three times, the skin glue isolated some parts of the eyelashes, which then required special cleaning to keep it conductive for the following applications.

The three applications ran with a time gap preset to sense voluntary blinking ( $0.5 \mathrm{~s}$ to $2 \mathrm{~s})$. A left and right wink, and both eyes closed triggered three different tasks in each application. Further research could include blinking combinations designed to produce more output options. For example, winking the left eye for four seconds followed by two seconds of both eyes closed could change a new image in the Superhero application.

\subsubsection{Conclusion and Future Work}

It is common knowledge that muscles control objects that are part of our daily lives like cars and computers. Makeup is also part of our daily lives and it is used to enhance the appearance of human bodies. Our proposal makes use of conductive makeup applied to the face to sense its muscles. In this prototype, we 
focus on the human agency for controlling the eyes' muscles, specifically voluntary blinking.

Applications were developed as proof of concept of the feasibility of Beauty Technology. Blinklifier uses blinking to control LED switching on an artistic head dress, and in the case of Arcana, for changing music tracks and visual images. Superhero also makes use of Beauty Technology for levitating an object.

Future work will include new Beauty Technology prototypes for sensing other facial muscles via conductive makeup. We will also explore blinking times and combinations for controlling different devices like air conditioning and hospital beds. Other future potential uses of this technology fall on opportunities for empowering individuals with disabilities, hands free interfaces, art performances that expose a gesture, unnoticed gestures as inputs, keeping people awake, and decoding blinking gestures for physical and physiological analysis.

\subsection{FX e-makeup}

FX e-makeup is a Beauty Technology prototype that makes use of special effects makeup that hides electronic components and is applied to the face to sense its muscles, acting as a second skin. Two applications will be presented, namely, Winkymote, an infrared remote control for individuals with quadriplegic disability and Kinisi, an artistic makeup that acts as an empowered second skin for triggering multiple devices.

In previous studies [90, 91, 92], Beauty Technology prototypes were developed using conductive makeup (describe above) to act as blinking switches. In this work, we propose FX e-makeup, another prototype that is focused on the human agency for controlling devices by sensing voluntary movements of facial muscles. It differs from: Vision Computing that provides methods for facial expression analysis by automatically recognizing facial motions and facial feature changes from visual information [94]; Bio-potential sensors such as Electroencephalogram (EEG), Electromyogram (EMG), and Electrooculogram (EOG) that have been used as inputs for several healthcare devices [94]; and Brain- Computer Interfaces that link the computer to the human nervous and muscular system for recognition of user's gestures in several hands free interfaces [95, 96, 97]. 


\subsubsection{FX e-makeup}

The senses of agency and of body ownership are two aspects in the bodily self which must be distinguished to identify different effects in body awareness [98]. A person has the capacity to act in the world through his sense of agency. Thus, intending and executing actions include the feeling of controlling one's own body movements, and, through them, events in the external environment [99]. Only voluntary actions produce a sense of agency and it is originated in neural processes responsible for the motor aspects of action [100]. On the other hand, the sense of body ownership refers to the understanding that the person's own body is the source of her movements or sensations, whether it was voluntary or not [10]. During a voluntary action, sensor mechanisms generate a sense of body ownership; however, only action provides a coherent sense of the whole body. Thus, the unity of bodily self-consciousness comes from action and not from sensation [99]. In this work, we propose an interface that makes use of the sense of agency inherent in humans to augment their capacities through voluntary muscle movements.

The muscles of the face are divided into two groups according to the function they serve: mastication muscles (four muscles attached to the bone and ligament that are mainly used for chewing and have a minor effect on expression) and expressive or "mimetic" muscles [101]. Facial expressions are caused by the movement of the mimetic muscles that are attached to the skin and fascia in the face, unlike other skeletal muscles that are attached to the bones. These groups of muscles move the skin, creating lines, folds and wrinkles, causing the movement of facial features, such as mouth and eyebrows. [101]. FX e-makeup sensors act as switches when strategically placed on these muscles.

Duchenne de Boulogne [102] found that some muscles that are activated by emotions are difficult to activate voluntarily. Ekman et. al. [103] also addresses the same difficulty in voluntary movements but got different results when children were asked to voluntarily activate muscular actions by imitating a model presented on a video monitor. The Gosselin et. al. [104] report is based on Facial Action Code System (FACS) to determine the extent to which adults are able to voluntarily produce facial muscular actions and also to discover the muscles that could be activated without the co-activation of other unwanted muscles. Twenty participants were asked to produce 20 facial action units, reproducing each action five times. Figure 22 indicates the percentage of participants who were able to activate the target action units at least once [104]. 


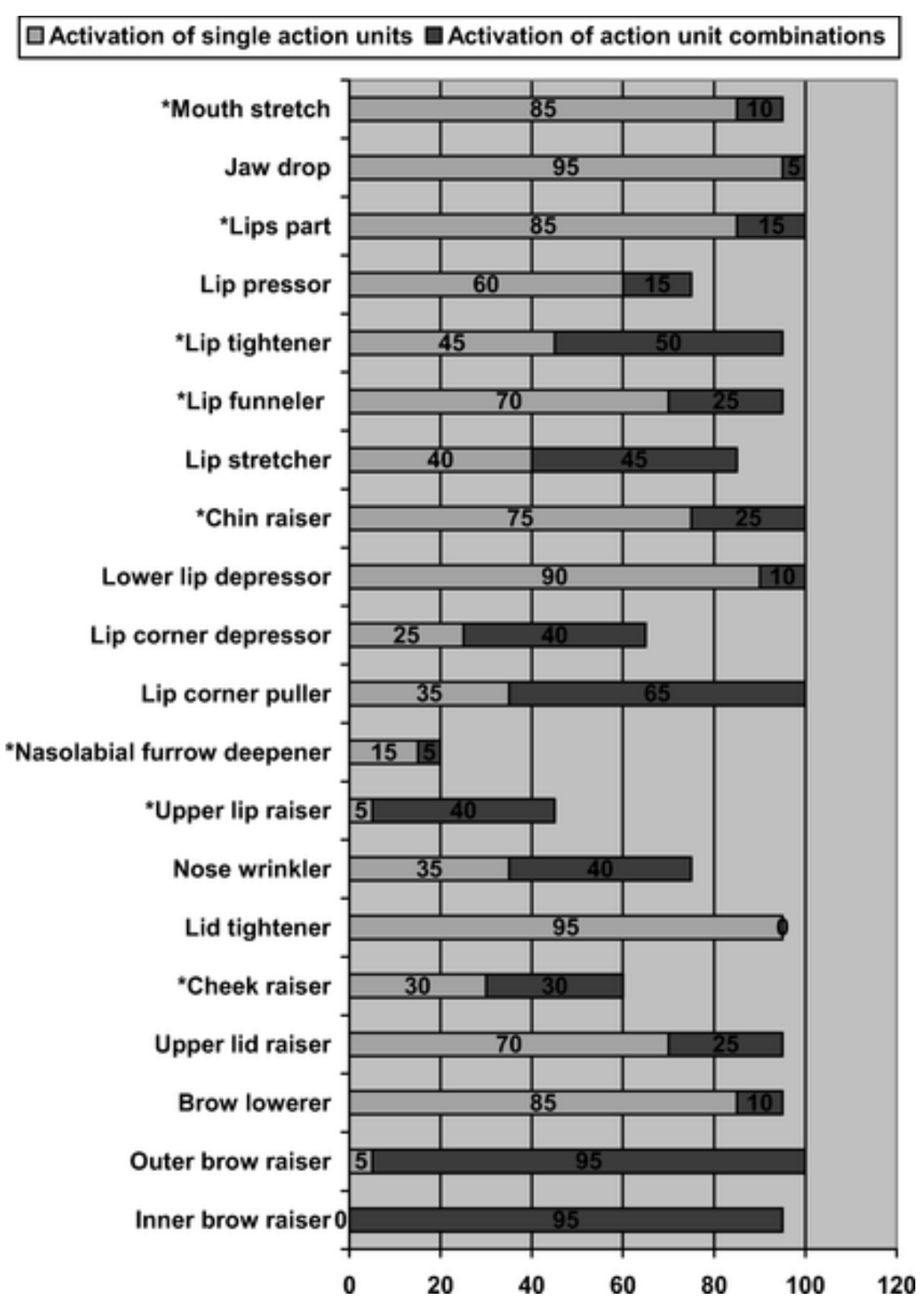

Figure 22. Percentage of participants who succeeded in activating the target action units [104].

Based on this report, we identified the action units that were used in our study. FACS' action units plus combinations that achieved more than 95\% of success (except for the lip presser that achieved roughly $75 \%$ of success) and had fewer associations with other movements were the ones that were considered in this work: jaw drop, lips part, lip corner puller, lid tighten, outer low brow raiser and lip pressor. Jaw drop and lips part action units had no associated movements. The lip corner puller action unit is associated with the check raiser 
action unit and the outer brow raiser is associated with the inner brow raiser one: in both cases, the associated movement is not constantly repeated. The chin raiser was the action unit most associated with other movements (5 times). The lower lip depressor has the chin raiser action unit as an associated movement. Both action units were discarded. The lid tighten action unit achieved $95 \%$ of success and got the lowest percent of associated movements. Figure 23a shows the sensors on these muscles.

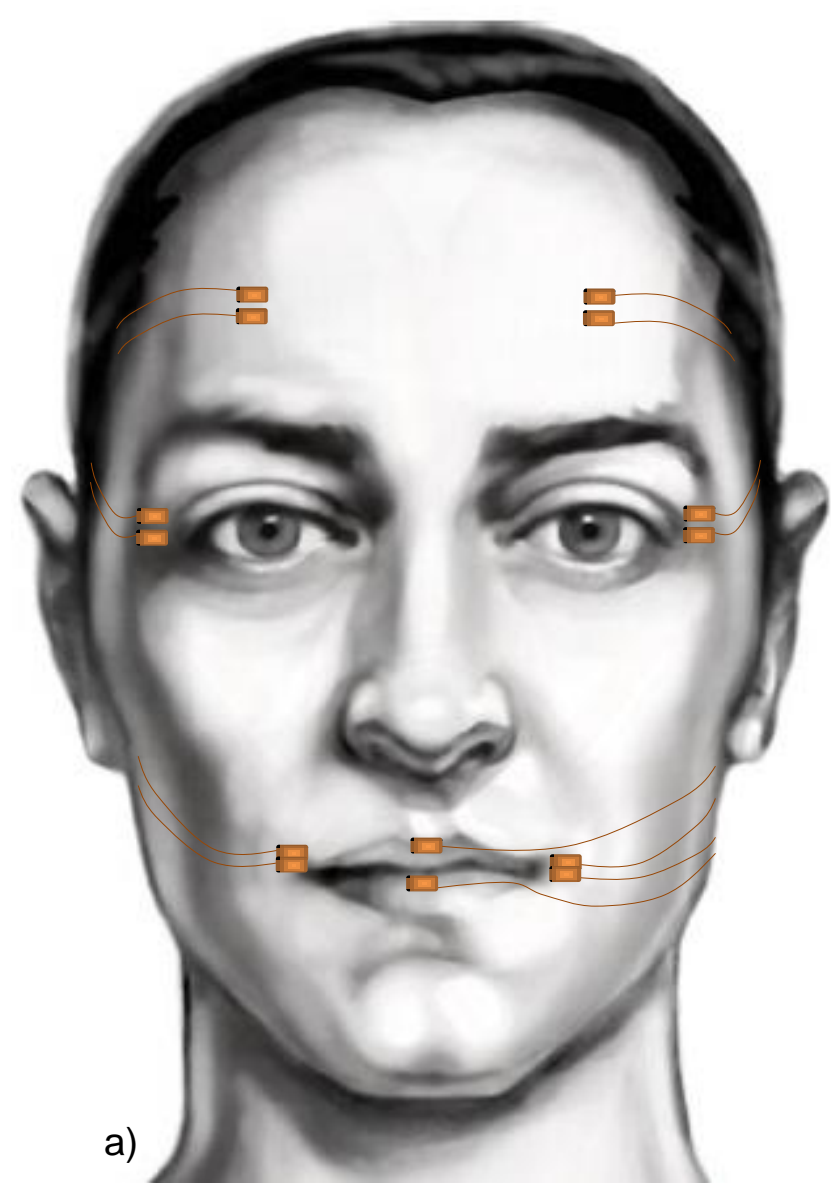

b)

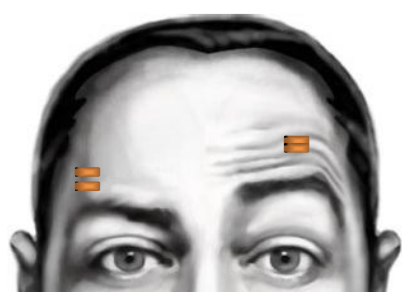

c)

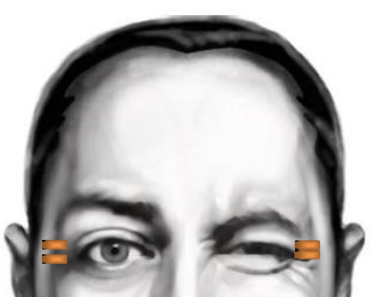

d)

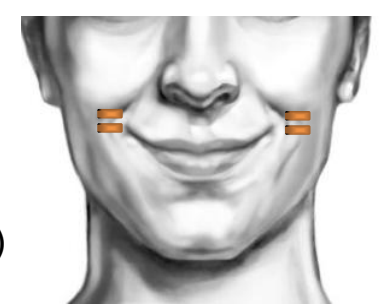

e)

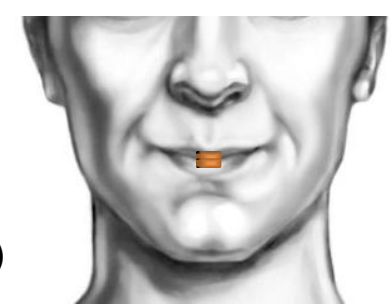

Figure 23. FX e-makeup interface. a) Sensors connected on muscles, b) eyebrow sensor, c) eyelid sensor, d) smile sensor, e) closing lips sensor.

Figure 23b shows the sensor located on the brow, associated with the outer low brow raiser action unit, and it is activated when the user raises his eyebrow and both contacts of the sensors are touched. Figure 23c shows the eyelid sensor (associate with the lid tightener action unit) that senses blinking when the lid is tightener and both contacts are touched. Figure $23 \mathrm{~d}$ shows the sensor associated with the Jaw drop, lips part, and lip corner puller action units. It senses a 
smile when there is no contact, in the opposite way to the other sensors. Finally, the sensor on Figure $23 e$ is associated with the lip pressor action unit and it activates when both lips are pressed together. Wires are hidden with FX makeup materials like ink and latex.

\subsubsection{FX e-makeup applications}

Kinisi and Winkymote were the applications developed for showing the feasibility of FX e-makeup.

\subsubsection{Kinisi}

Figure 24 presents Kinisi, a FX e-makeup application. It tries to answer the question: "Could your skin act as an interface?" with an artistic video [105] that exposes the use of FX e-makeup for activating different light patterns with smiles, winks, raised eyebrows and lips [30]. The voluntary movements approximate the points closing circuits. According to one's face, action units are identified and marked as it is show in Figures 24a and 24b. A first layer of latex is applied to isolate the skin from the electronics. Sensors are precisely glued to the latex mask on the chosen points. LEDs are placed on the mask and between braids. Finally, face paint was used to color the user's face black.

\subsubsection{Winkymote}

Numerous approaches have been tried to develop technological solutions to facilitate independent communication and mobility for individuals with disabilities, among these the mouth stick, sensors activated by blinking, respiration and head movement $[107,108]$. A communication interface controlled by voluntary blinking that activates infrared controlled devices simulating a remote control is being developed for individuals with quadriplegic disability.

Felipe, a 33-year-old M.Sc. student in administration, inspired Winkymote. He hurt himself playing jujitsu and now has had quadriplegic disability for 13 years. Felipe uses a speech recognition system keyboard replacement to control his computer but, unfortunately, depends on others to do common activities such as changing television channels.

Winkymote (Figure 25) is an infrared-controlled interface that uses FX emakeup sensors connected to an infrared-transmitting module mounted on the user's necklace. These sensors are placed close to the outer end of each eye, 
i.e., close to the lid tighten action unit. They are connected through wires to the infrared-transmitting module mounted on his chest. Whenever he winks tightly, the switch closes sending a digital signal to the microcontroller that activates sound as feedback to inform an infrared LED that it is sending the appropriate sequences for triggering the television. Blinking with his left or right or both eyes turns the television on, off or changes the channels up and down.

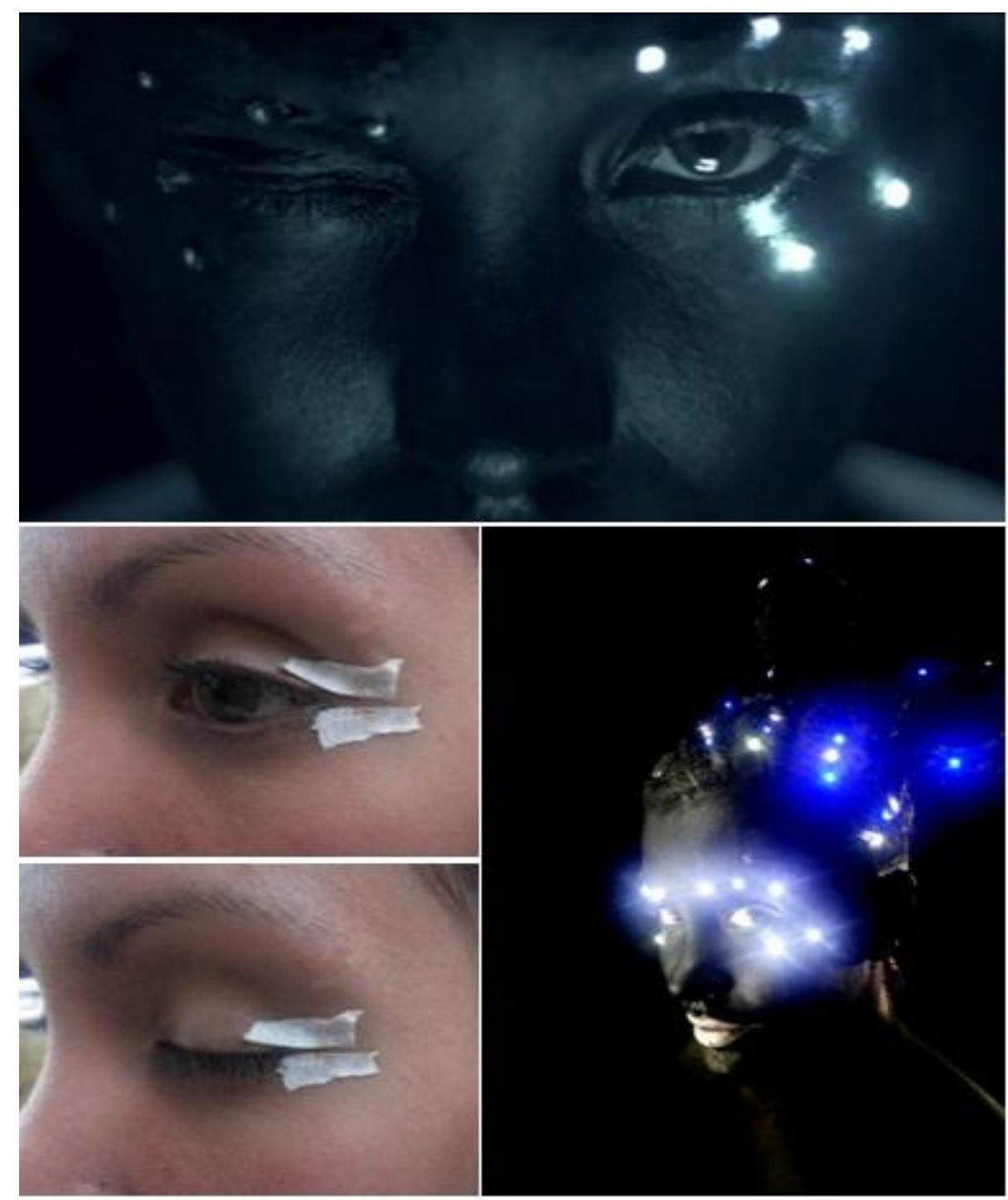

Figure 24. Kinisi.

a) Kinisi closing the right eye, b) Eyelid in a neutral position, c) Eyelid up closing the circuit, d) Kinisi wearing FX e-makeup. 


\subsubsection{Lessons Learned}

The first FX e-makeup prototype comprised gelatin powder without flavor, distilled water and glycerin. This kind of FX makeup is often used for creating prosthetics such as wounds, scars, burns and blisters. Finding the proper makeup consistency depends on its preparation given that it requires heating the ingredients. Our initial results were too thick and had the tendency to fall off depending on the skin properties and the user's movements. Three participants worn the makeup for six hours but it didn't work on Felipe, whose makeup fell off after one hour, because of his oily skin. After deciding to use hydrogel, which helped fix the electronics, we had to give up for the same reason: his oily skin. Finally, we decided to use liquid latex. It was applied to the skin using a disposable sponge taking about five minutes to dry. As it dries it turns to a rubbery consistency and is molded to the user's skin. Then, more layers were applied to the skin to embed and isolate the electronic components.

The face has over 40 anatomically independent muscles referred to as specific action units that could be co-activated. The corrugator muscle group, for instance, which brings the brows down and together, is comprised of three muscles that are normally activated together. Although, the sensors on the FX emakeup action units could operate independently, not all combinations are possible like concurrently raising the left eyebrow and tightening the left eyelid, and raising each eyebrow independently.

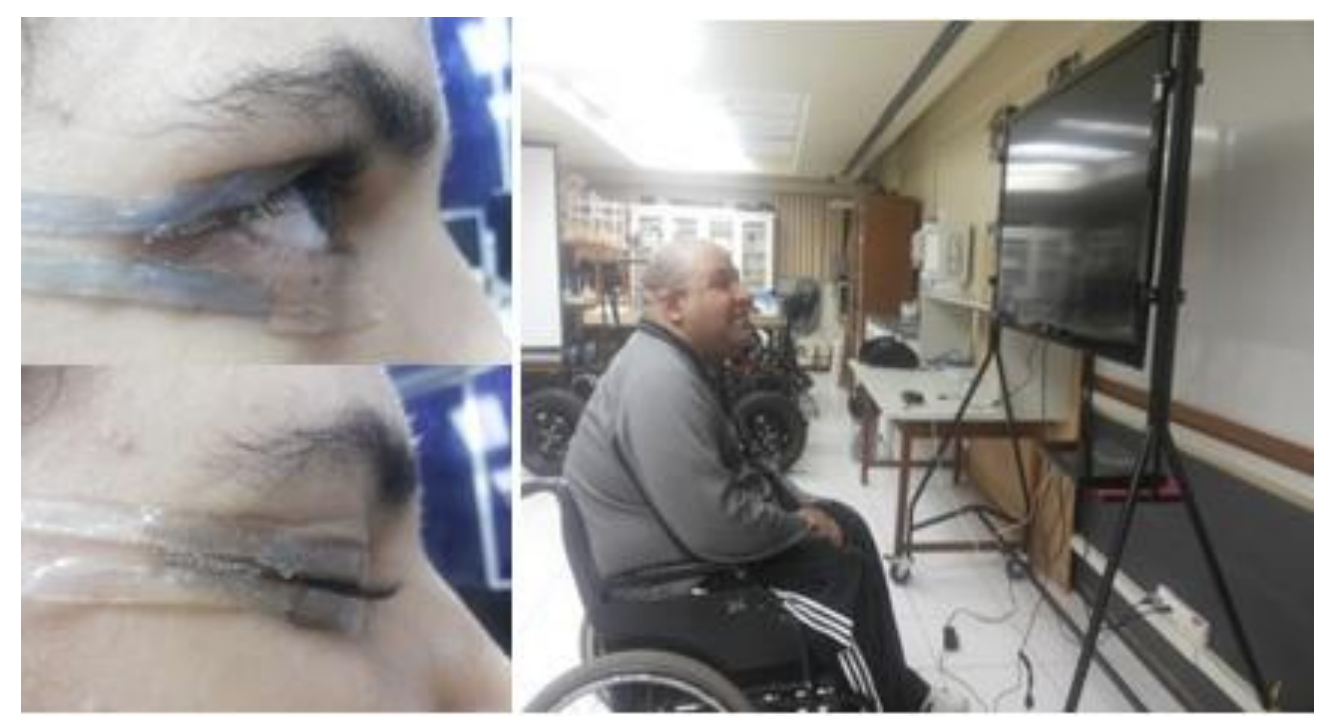

Figure 25. Winkymote, an infrared-controlled interface for individuals with quadriplegic disability. 
Action units' activation differs in duration and intensity. In contrast to previous works $[90,91,93]$ where a preset time interval for sensing voluntary movements was defined, given that FX e-makeup sensors are precisely located, they are only activated when the intensity of the movement reaches a high level.

FX e-makeup may be used to control multiple devices. Sensors could be connected to a variety of devices providing user feedback and communication with other devices. For example, a device for changing slides (closing the right eye the presentation moves forward to the next slide) was prototyped to work with Winkymote.

\subsubsection{Conclusion and Future Work}

This work proposes FX e-makeup as a Beauty Technology prototype to sense voluntary facial movements for triggering multiple devices. FX e-makeup is molded as a second skin over the user's face to embed electronics.

Action Units were selected based on a previous study that identifies the success rate to activate an action unit and the other muscle's movements associated with it. Jaw drop, lips part, lip corner puller, lid tightener, outer low brow raiser and lip pressor were the action units chosen as inputs for FX e-makeup. The FX e-makeup sensors act as switches that are activated with the folding of the skin.

Two applications showed the feasibility of this technology. Kinisi is an artistic application that uses muscle movements to activate light patterns on the face and hair. Winkymote is an application for individuals with quadriplegic disability that controls infrared devices like television sets.

Future work will include new Beauty Technology prototypes to sense other facial action units via FX e-makeup. Sensors and their duration/intensity level combinations connected to other action units will be incorporated to FX e-makeup applications. We also intend to expand FX e-makeup sensors to explore neck movements for controlling different devices like air conditioning and hospital beds. Other future potential uses of this technology will explore novel hands free interfaces like dealing with amplifying or unnoticed gestures, keeping people awake, and decoding blinking gestures for physical and physiological analysis.

As seen above, there are several possibilities to turn FX e-makeup prototypes into products. Firstly, there are market challenges that should be overcome in order to deliver value to their potential customers. How to segment the market? 
Who are the potential targets? How to position the new products? These are important decisions to be taken by the holders of this promising Muscle Based Interface technology in the future. 


\section{5. \\ Arm/Hand Movement}

This chapter describes the materials and the prototyping process used in the making of Beauty Tech Nails exemplifying its application in everyday beauty products.

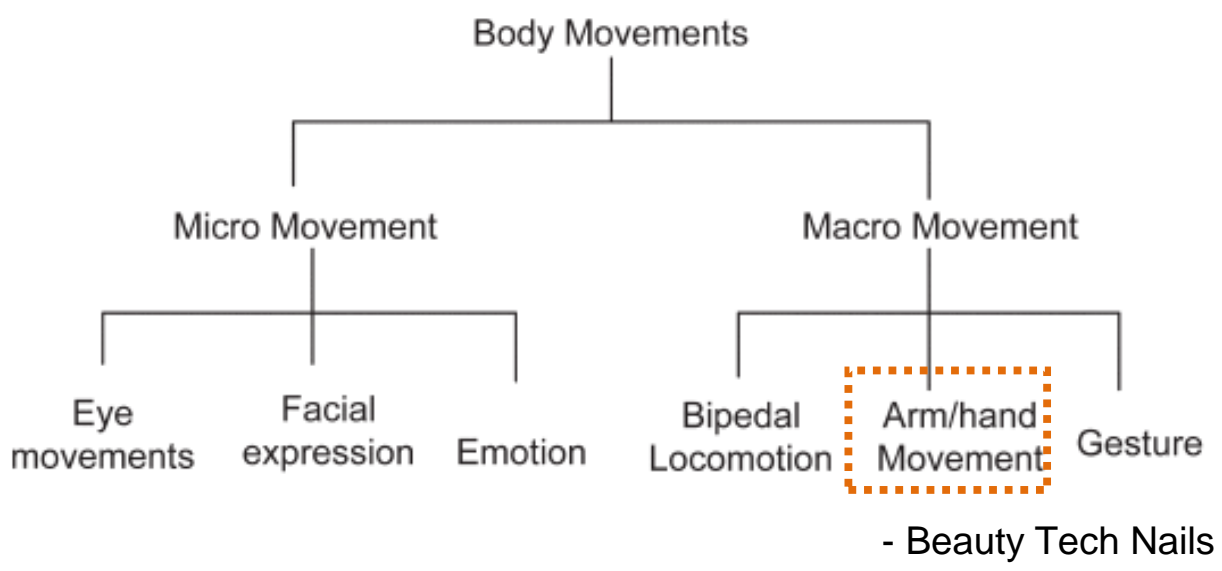

Figure 26. Adapted from "Taxonomy of Body Movements" [24].

\subsection{Beauty Tech Nails}

This section introduces different approaches for the use of fingertip based technology. It presents the prototype design, and the materials used to hide RFID tags into gel and fake plastic nails. This section shows three examples of interaction through: water (AquaDJing), another wearable (Gimmickiano) and another smart object (Twinkle Nails) just by approximating the fingernails. Finally, a discussion, the conclusions, and future work of Beauty Tech Nails are presented.

\subsubsection{Beauty Tech Nails with RFIDs}

Due to increasing advances in electronics, it is possible to have even smaller and more powerful devices. However, human factors do not change that 
fast: fingers retain the same size and shape. Even more, the interaction with a piano, a keyboard and any press-and-play object through a sequence of finger movements remains the same. The same could be said regarding the motor learning skills that humans had to gain with their fingers in order to interact with specific targets [108]. In addition, finger based interactions tend to be faster than interaction based on other body parts. Card et al. [109] conducted experiments comparing interactions with input devices through different body parts (fingers wrist, arm). They demonstrated that the motor cortex is highly devoted to muscles groups like fingers. These findings determined that finger based input devices have a promising chance to succeed.

The major challenge that wearable input devices are facing today is to ensure that they are created as unobtrusive devices [110]. Related works aforementioned showed different finger-worn interfaces where batteries, wires and circuits are exposed and, therefore, they are not yet accepted as everyday objects. Beauty Tech Nails are plastic or gel nails that hide electronics like RFID tags, small magnets and conductive polish enabling the wearer to interact with objects in the environment $[111,112]$. This paper focuses on the ones that hide RFID tags.

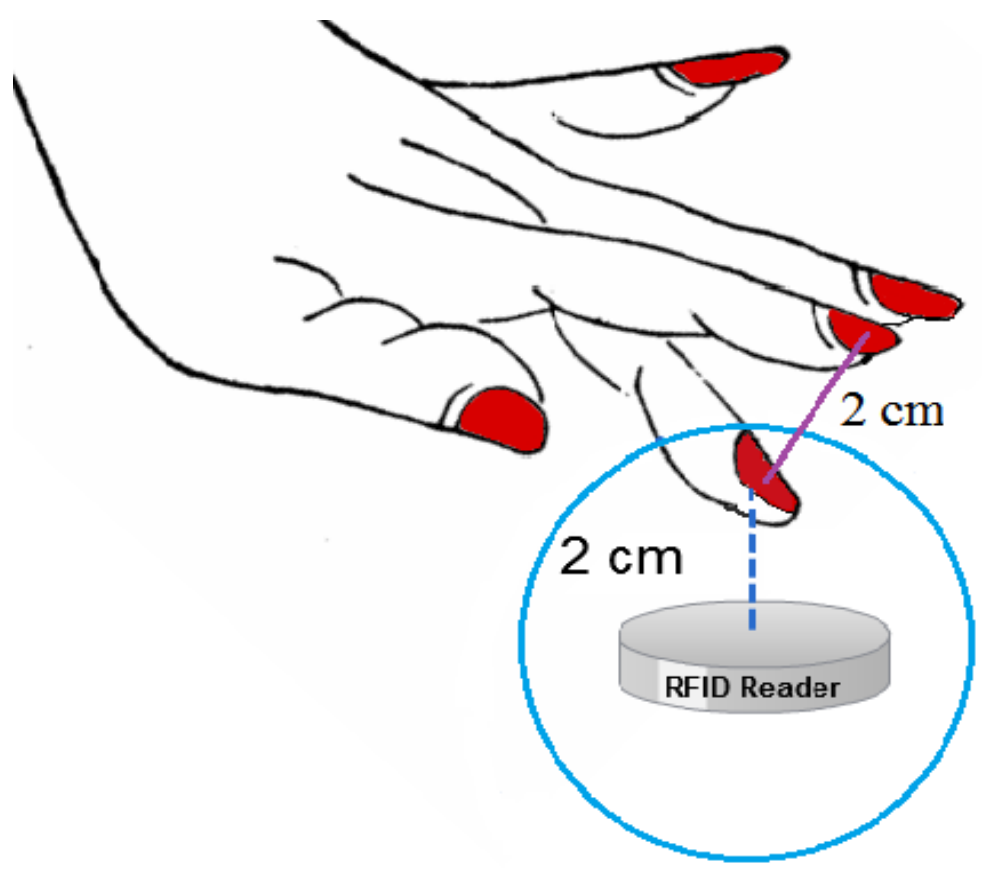

Figure 27. Interaction between Beauty Tech Nail and the reader. 


\subsubsection{RFID Based Interaction}

The rapid adoption of RFID systems creates opportunities for new and innovative services. It enables organizations to deliver value-added applications related to the tracking and intelligent management of anything tagged with an RFID tag [113]. RFID tags fall into two categories: Active tags are read/write devices that require a power supply, while passive tags are generally read only eschewing batteries. Passive tags draw their power from the reader through inductive coupling that requires close proximity. Beauty Tech Nails RFID tags fall in the latter category by using an RFID glass-capsule-tag embedded into each fake nail. A 32-bit non-reprogrammable unique ID that works at $125 \mathrm{KHz}$ frequency is used. The RFID reader [114] recognizes a tag within about $2 \mathrm{~cm}$ of distance as it is shown in Figure 27. We chose this short distance reader due to the interspaces between fingers and their motion possibilities, because, whenever a specific finger is interacting with the reader, this finger is in the reader's range and there is a space between fingers of about $2 \mathrm{~cm}$. With a long distance reader all Beauty Tech Nails would be recognized at once.

The main advantages of RFID systems are the non-contact and non-line-ofsight characteristics of the technology. Tags could be read through a variety of visually and environmentally challenging conditions such as snow, ice, fog, paint, grime, inside containers and vehicles and even insider storage [114]. A specific advantage of passive tags is that they do not require batteries or maintenance, have an indefinite operational life and are very small.

\subsubsection{Prototype Design}

The chosen RFIDs' dimensions are $12.25 \mathrm{~mm}$ width by $1.93 \mathrm{~mm}$ in diameter. They are hidden either into plastic/acrylic gel sandwich nails or salon gel nails. The former nails are easily attached and removed from the natural nails using common glue for false plastic nails. In this case, tags are sandwiched between the fake plastic nails and the acrylic gel.

Gel nails are a type of artificial nail that most closely resembles natural nails. They could be kept on fingers for more than five weeks. The gel is applied to the natural nails in several thinly layers, with each layer being cured under a UV lamp for about two minutes each. A tag is placed on the top of the basecoat after it dries. Then, several thin gel layers are applied until they completely cover 
the RFID. A decorative design using nail polish is applied at the end of the process. Figure 28 shows this process.

\subsubsection{Interactive Possibilities and Applications}

In this section, Beauty Tech Nails applications are presented. They embed RFID tags into false nails and take advantage of the RFID possibilities for presenting different interactions: non-contact interaction, unusual interactions, and wearables interaction.

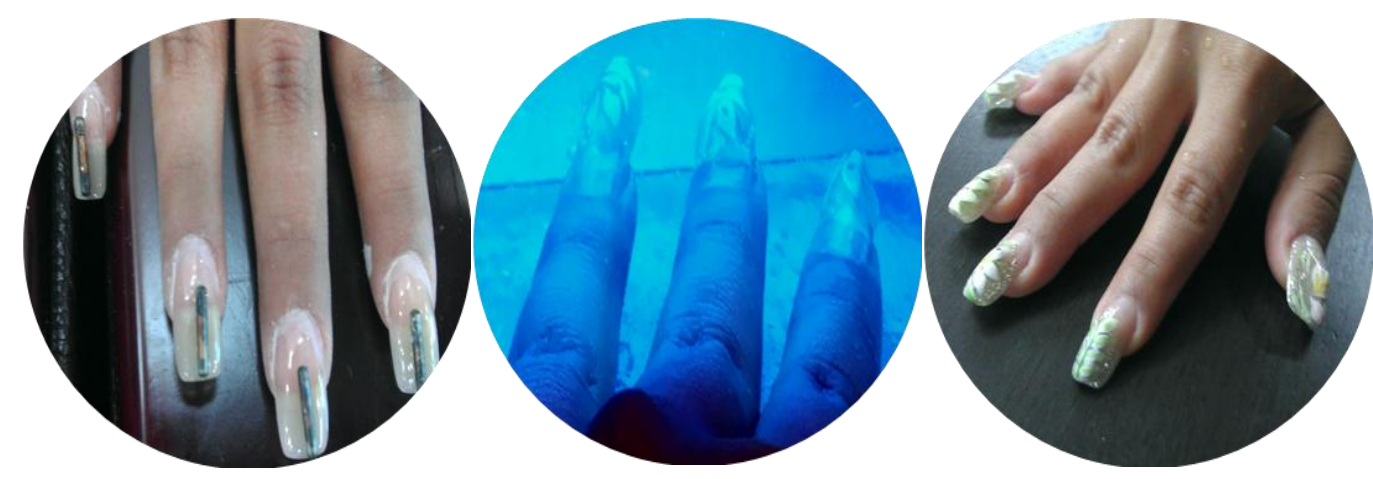

Figure 28. Prototyping Beauty Tech Nails. Gel Nail process.

Step 1. RFID tag placed on the top of the dried basecoat gel.

Step 2. Curing gel layers.

Step 3. Decorative nail design.

\section{- Non-contact Interaction}

Using the RFID's proximity feature, the fingernail does not need to touch the smart object to identify it. Whenever the finger is closer than $2 \mathrm{~cm}$ from the reader, the unique ID would be recognized. Twinkle Nails application (Figure 29) is a musical combo comprising a Beauty Tech Nail and a box that hides a RFID reader that translates each ID tag into a different note.

\section{- Unusual Interactions}

An RFID reader recognizes tags through different materials like water, glass and wood and also through different states of matter like ice and vapor. AquaDJing makes use of Beauty Tech Nails to interact through water. RFID nails are detected without touching the "DJ Controller" that is sitting at the bottom of a water container. Figure 30 shows the deejay's performance mixing 25 tracks and an opera singer playing sound effect by "touching" the water. While Beauty Tech Nails on the right hand are recognized as tracks, the deejay controls sound ef- 
fects and mixes them with the left hand nails. The controller is connected to a computer that plays the music effects and tracks while visualizations are being displayed.

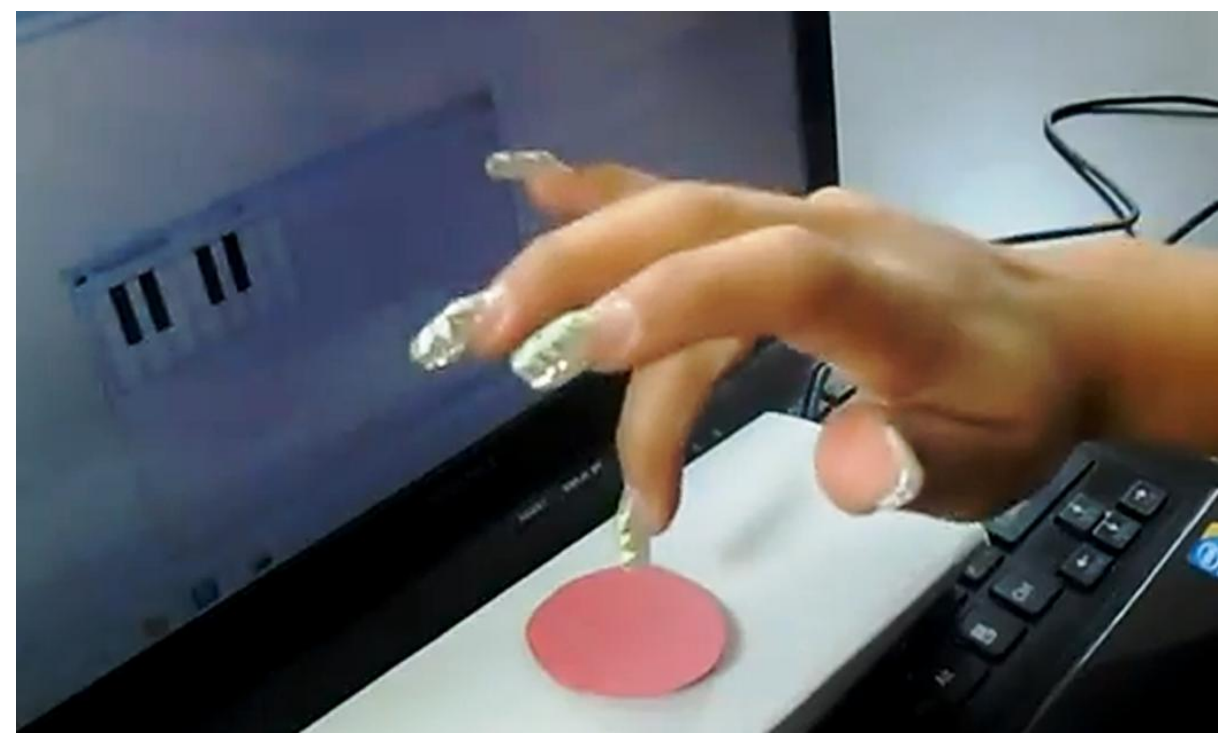

Figure 29. Twinkle Nails, non-contact piano playing

\section{- Wearables Interactions}

RFID readers could also be embedded into wearable devices to add extra mobility to the Beauty Tech Nails', which is the case with Gimmickiano (Figure 31 ). It is a wearable piano belt that a performer wears while she moves around the auditorium. The wearable sends the notes to the computer through a radio module, and the notes are played and displayed in a piano visualization when she approximates each fingernail to her belt.

\subsubsection{Conclusion and Future Work}

Beauty Technology is proposed as a novel Wearable Computing approach that hides electromagnetic components in beauty products worn on the body surface. Some are easy to attach and remove, and all of them are ergonomic and enhance one's looks.

There are advantages of using low frequency RFID tags were appropriate in order to create interactive applications with Beauty Tech Nails. They are fashionable, wireless and always available and need no power required components. A small glass capsule RFID tag is protected for everyday use by acrylic gel in 
plastic nails and by salon gel in gel nails. These tags need no contact for tag detection and recognition even when interacting through different materials and states of matter. Short distance passive tag readers make use of the interspaces between fingers for disambiguating targets. This technology identifies individual fingers motion, thus constituting a different sub-area of gesture recognition.

Wearables and smart objects were created to interact with Beauty Tech Nails. Applications for showcasing without touch interaction (Twinkle Nails), for interacting in unusual conditions like through the water (AquaDJing) and for adding extra mobility when interacting with wearables (Gimmickiano) were prototyped.
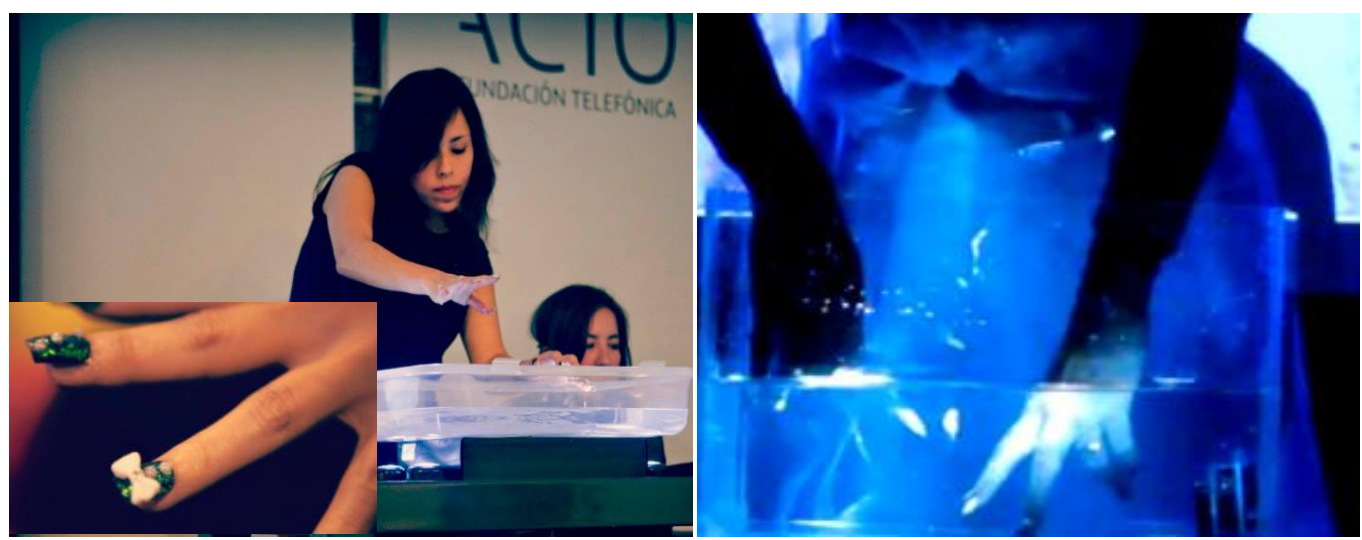

Figure 30. Unusual interactions. 30.1. AquaDJing, mixing tracks touching water surface. 30.2. Sentido Aware, Opera singer playing tracks and sound effects touching into the water.

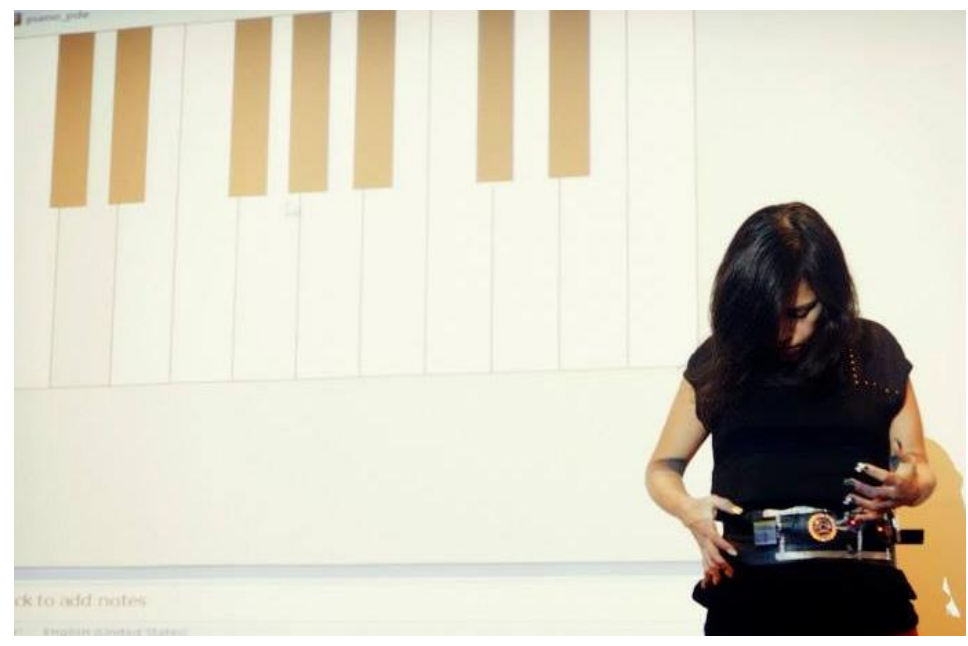

Figure 31. Gimmickiano, wearable that recognizes RFID nails. 
Future Beauty Tech Nails will combine low and high frequency RFID tags, magnets and conductive nail polish. As the miniaturization of sensors, batteries and other electromagnetic components evolves, these could be added into new Beauty Tech Nails. Then, these nails will also interact with a variety of different smart objects in the Internet of Things. Future applications could substitute known input devices for Beauty Tech Nails adding new kinds of interactions to the repertoire. 


\section{6 Conclusions and Future Work}

Wearables are taking on a more essential role in our daily lives, making possible other forms of communication and computing. This work presented our approach to using the human body as an input device. We introduced the term Beauty Technology as an emerging field in Wearable Computers. It intended to follow the Disappearing Computer paradigm that hides technology into everyday objects. Thus, due to the acceptance and daily use of beauty products, electronic components were embedded into them for creating this interactive computing platform.

Wearables are traditionally placed on clothes and accessories, but our approach placed them directly on the surface of the body. We proposed a classification of On Body Technologies for identifying our application context. In this way, our prototypes were placed on the hair, nails and skin.

Wearables are improving the way they respond to a wider range of human inputs. We analyzed micro and macro body movements to propose prototypes that react to voluntary movements. The micro movements sensed were the Facial expressions of blinking, smiling, raising eyebrows and closing lips by the Conductive Makeup and FX e-makeup prototypes. Finger movements that related to the Arm/hand macro movements were sensed by the Beauty Tech Nails prototype.

Conductive Makeup is a Beauty Technology prototype that made use of Conductive Eyelashes. They are false eyelashes that were chemically metalized to be able to sense blinking. When the eyelashes touched each other by blinking during a period of time, the switch was on and then, the digital signals went to the microcontroller through conductive channels of eyeliner. The eyeliner was created from conductive stickers in a black eyeliner shape. Blinklifier, Arcana and Superhero were the applications of this technology.

FX e-makeup is a prototype that senses voluntary smiling, blinking, raising eyebrows and closing lips. Sensors were placed on the face musculature that sensed the skin folds. Winkymote and Kinisi were presented as the applications of this technology.

Beauty Tech Nails embedded RFIDs into fake plastic nails. Interfaces that react without touch, into the water and through wearables show the possibilities 
of this technology. AquaDJing, Sentido Aware, Gimmickiano and Twinkle Nails applications showed the feasibility of this technology.

Unlike other wearables for sensing facial expression, Beauty Technology prototypes do not make use of video cameras, electromyogram or galvanic skin response. We proposed a new technology based on Conductive Makeup and FX e-makeup sensors. They minimize the use of intrusive devices on the face, giving the wearer the possibility of motion and without distracting the wearer's attention away from their daily life activities.

This work presented an exploration between the body, technology and interaction. Consequently, these prototypes were created in a multidisciplinary fashion. Design, chemistry, body structure, electronics and software were the basis for creating this technology. This opens new possibilities of research in several areas.

\subsection{Contributions}

At the completion of this project, our contributions are:

1. We proposed and developed a novel wearable computing field called Beauty Technology. It reads the human body as an interactive computing platform.

2. An On-Body Technologies Classification is presented for placing technologies around the body and for defining the Beauty Technology context of application.

3. A muscle-based interface was proposed as the interactive strategy. Prototypes for sensing blinking, facial muscles movements and finger movements were developed.

4. Beauty Technology prototypes that are on-body hidden sensors could interact with other devices such as Wearables on clothes, appliances and a PC.

5. Conductive Eyelashes is a novel material that keeps the natural black appearance of fake eyelashes but makes it possible to create applications for sensing blinking.

6. FX e-makeup sensors propose a new technology for sensing facial movements.

7. Beauty Tech Nails do not need to touch the object to activate it. Therefore, they can interact with contactless interfaces or interfaces that place any other element around the reader range such as water, sand 
and wood. We used the advantages of RFIDs to differentiate fingers, users and identify users.

\subsection{Future Work}

A voluntary movement triggered a device by using a preset duration in Conductive Makeup prototype and by the maximum intensity of the movement in the FX e-makeup prototype. Combining the duration of an expression, the intensity required and different muscle movements could provide more interactive options. For example, the combination of blinking the left eye for two seconds and smiling for three seconds could turn the radio on.

Beauty Technology prototypes interact with other devices through physical wires, radio modules and infrared remote controllers but it is not limited to these technologies. Different devices could be used for communication such as Bluetooth.

Beauty Tech Nails could embed other technologies. For example, magnets for amplifying the wearers' capabilities by extending the touch sense for reading magnetic fields and also giving them access to different objects. They could interact with tablets and smartphones (those having magnetic sensors) and smart object with embedded smart switches. Also conductive nail polish could be created to interact with devices with capacitive sensors such as a tablet.

As Beauty Technology could be constantly sensing personal space, personal data could be saved for quantify yourself applications. For example, blinking exposes psychological and physical states: a low blinking rate is indicative of a bored or uninterested state [115]. One can easily envisage the benefits of a natural and unobtrusive makeup that understands this blinking rate, returns this information to the wearer enabling her to modify her posture and behavior.

Beauty technology gives wearers the opportunity to experiment in the customization of its objects, highlighting their personalities and even more, keeping the mystery of hidden technology, changing its appearance each day. They could play by changing the makeup color and eyeliner intensity, nail polish and decoration while the functionality remains the same.

Through the development of novel materials and electronic components, we can expect Beauty Technology prototypes with a suitable visual aesthetic and more sensors and actuators. For example, our future project is called Hairware. This is a chemically metalized hair extension that works as a capacitive sensor to trigger devices by identifying gestures made with the hair. Moreover, we are look- 
ing to exchange knowledge with other specialist like nanotechnologists, neurophysicians and psychologist.

\subsection{Published Work}

Publications, Demos, Exhibitions, Awards and Media Coverage related to Beauty Technology are listed below.

\subsubsection{Publications}

The following list presents our publications related to Beauty Technology:

- Vega, K., Fuks, Beauty Tech Nails: Interactive Technology at your Fingertips. TEl '14, 8th International Conference on Tangible, Embedded and Embodied Interaction.

- Vega, K., Fuks, H. Beauty Technology as an Interactive Computing Platform. In ITS '13: Proceedings of the 2013 ACM International Conference on Interactive Tabletops and Surfaces.

- Vega, K., Fuks, H. Beauty Technology: Muscle based Computing Interaction. In ITS '13: Proceedings of the 2013 ACM International Conference on Interactive Tabletops and Surfaces.

- Vega, K. Exploring the power of feedback loops in wearables computers. Proceedings of TEI '13, 7th International Conference on Tangible, Embedded and Embodied Interaction, Volume 1, pp. 371-372. Barcelona: ACM, 2013. ISBN 978-1-4503-1898-3. DOI: 10.1145/2460625.2460699.

- Vega, K.; Flanagan, P.J.; Fuks, H. Blinklifier: A Case Study for Prototyping Wearable Computers in Technology and Visual Arts. Proceedings of $\mathrm{HCl}$ 2013, Design, User Experience, and Usability. User Experience in Novel Technological Environments, Volume 8014, pp. 439-445. ISBN 978-3-64239237-5. ISSN 0302-9743. DOI: 10.1007/978-3-642-39238-2_48.

- Vega, K.; Fuks, H. Empowering Electronic Divas through Beauty Technology. Proceedings of $\mathrm{HCl}$ 2013, Design, User Experience, and Usability. User Experience in Novel Technological Environments , Volume 8014, pp. 237-245. ISBN 978-3-642-39237-5. DOI: 10.1007/978-3-642-39238-2_26.

- Flanagan, P.J.; Vega, K. Future Fashion - At the Interface. Proceedings of $\mathrm{HCl}$ 2013, Design, User Experience, and Usability. Design Philosophy, Methods, and Tools, Volume 8012, pp. 48-57. ISBN 978-3-642-39228-3. DOI: 10.1007/978-3-642-39229-0_6. 
- Flanagan, P.J.; Vega, K.; Fuks, H. Blinklifier: The power of feedback loops for amplifying expressions through bodily worn objects. Proceedings of APCHI 2012, The 10th Asia Pacific Conference on Computer Human Interaction , Volume 2, pp. 641-642. Matsue, 2012. ISBN 978-4-9906562-0-1.

\subsubsection{Awards}

The following list shows the awards won during the PhD project.

- First place award at the International Conference on Tangible, Embedded and Embodied Interaction (TEI 2013). Design Challenge. Project: Superhero. February 2013. Barcelona, Spain.

- Third place award in the PhD Projects Category at the Latin-American School on Software Engineering (ELA-ES 2013). Project: Beauty Technology as an Interactive Platform 09-12 July 2013, Rio de Janeiro, Brazil

- First Prize. Prize: Innovations for a better life. XVI Mostra PUC- PhD Project. August 16th 2013. Rio de Janeiro, Brazil.

- Second Prize. Best papers: "Uma Abordagem Sistemática de Prototipação Colaborativa para a Criação de Tangíveis". Brazilian Symposium in Collaborative Systems (SBSC 2013).

\subsubsection{Exhibitions and Demos}

Beauty Technology applications were exhibited in different conferences and fairs. The following list presents the exhibitions and demonstrations related to Beauty Technology applications.

- Wearable Futures (UK, 2013). Project Twinkle Nails.

- Women 2.0. Fashion Show (USA, 2013). Projects: AquaDJing, Superhero.

- UIST'13, 26th ACM Symposium on User Interface Software and Technology. Student Contest (Scotland, 2013). Project: AquaDJing.

- Maker Faire Bay Area (USA, 2013). Projects: Superhero, Twinkle Nails.

- Mostra PUC (Brazil, 2013). Project: Twinkle Nails.

- TEl'13, 7th International Conference on Tangible, Embedded and Embodied Interaction. Design Challenge (Spain, 2013). Project: Superhero.

- Conversatorio Fundación Telefónica. Arte y Estética en Wearable Computers (Peru, 2013). Projects: Arcana, Gimmickiano, AquaDJing.

- Sydney VIVID festival. Haptic Interface Pop-Up exhibition (Australia, 2013). Project Blinklifier. 
- Asian Premiere of Multimedia Art: New York Paris Hong Kong Change your Perception (Hong Kong, 2013). Project Blinklifier.

- JMGA 15th Biennial Conference Participation + Exchange. Participate Exhibition. (Australia, 2012). Project Blinklifier.

- Haptic Interface Exhibition (Hong Kong, 2012). Project Blinklifier.

- Beyond Wearable (China, 2012). Project Blinklifier.

\subsubsection{Future presentations}

We will be presenting Beauty Technology project in the following conferences:

- Demo and paper presentation: TEl'14, 8th International Conference on Tangible, Embedded and Embodied Interaction. Demo Session (Germany, 2014). Project: AquaDJing, Twinkle Nails.

- Session Chair and paper presentation: HCIl'14, 15th International Conference on Human-Computer Interaction (Greece, 2014). Session: "Novel Wearable Interfaces: Beauty Technology".

\subsubsection{Media Coverage}

Beauty Technology prototypes and applications attracted the following press coverage. The list contains several press releases talking about this technology.

\section{Fast Company}

These Fake Eyelashes Can Control Your TV

http://www.fastcoexist.com/3025541/these-fake-eyelashes-can-control-your-tv Thru, 06 Feb 2014

Wearable tech as makeup could help quadriplegics control their environments with the wink of an eye.

\section{Wired UK}

Superhero remote control eyelashes: the wearable tech we can get onboard with http://www.wired.co.uk/news/archive/2014-01/28/motion-control-makeup Tue, 28 Jan 2014

When 33-year-old quadriplegic Felipe Esteves saw Katia Vega levitate a small 
drone just by blinking at it, he knew that was the kind of superhero he wanted to be. Wearing a white wig to keep her secret identity intact, channeling X-Men's Storm, Vega was demonstrating her superhero tech at an expo. Each time she blinked with purpose, a tiny circuit nearly invisible to onlookers completed and instructed a controller to move the drone. That circuit was hidden under her wig, and was completed every time a pair of metallic false eyelashes met for a long enough time and connected to conductive eyeliner Vega was wearing. Signals were transmitted to a Zigbee radio, with the receiver kept in the superhero's handbag. Sometimes, her blinks instructed animated images that read "POW, Bam, Zap" to pop up.

\section{PSFK}

Makeup with embedded electronics helps the disabled control their devices http://www.psfk.com/2014/01/embedded-electronic-makeup.html

Fri, 24 Jan 2014

Advancements in wearable technology enable people with disabilities to carry on with normal daily functions.

\section{Cisco}

Startup trends for 2014 http://newsroom.cisco.com/feature-content?type=webcontent\&articleld=1308686 Mon, 13 Jan 2014

A look at the wearable, shareable \& social trends you'll see in the coming year..

\section{PSFK}

The Future of Wearable Tech. Key trends driven the Form and Function of Personal Devices

http://www.psfk.com/publishing/future-of-wearable-tech

Wed, 8 Jan 2014

This report examines 10 key trends that are impacting the future of wearable technologies with a focus on the basic features, form and functions of these devices and technologies and what they might replace. Aided by the increased processing speed of chips, capacity of batteries and precision of sensor technologies, devices are becoming smaller, faster and more feature heavy, nearly replacing entire electronic categories in the process and furthermore impacting the 
way we live, work and socialize. As we plan for the future, PSFK Labs in collaboration with $\mathrm{iQ}$ by Intel is excited for the opportunity to contribute its point of view to this ongoing conversation.

\section{Mashable}

Smart Eyelashes and Fingernails: The Next Wave of Wearable Tech http://mashable.com/2013/12/21/programmable-makeup/

Sat, 21 Dec 2013

It was crowded on the sidewalks in Hong Kong. Early morning commuters, shoulders tightly pressed against the strangers walking next to them, moved in a sluggish blob through each brimming intersection. Katia Vega didn't mind the congestion. If anything, it made for ideal people-watching.

\section{Women 2.0}

Katia Vega to Showcase Aqua DJ Set and Drone That Reacts to Body Movement http://women2.com/katia-vega-showcase-aqua-dj-set-drone-reacts-bodymovement/\#G2p5hfVrbfEoDQwd.99

Tue, 12 Nov 2013

Our newest fashion show addition is pushing the boundaries of wearable tech. Learn what she will be showcasing at our conference.

\section{Fashioning Tech}

It's All in a Wink http://www.fashioningtech.com/profiles/blogs/it-s-all-in-a-wink-1

Thru, 31 Oct 2013

Katia Vega is a Beauty Tech Designer and is currently a PhD candidate in Computer Science at the Department of Informatics from the Pontifical Catholic University of Rio de Janeiro (Brazil) under the supervision of Prof. Hugo Fuks. She describes beauty technology as an emergent field in wearable computer using software in innovative ways.

\section{Nextmedia}

\section{戴假睫毛通電 眨眼開燈}

http://hk.apple.nextmedia.com/international/art/20131026/18479867

Sat, 26 Oct 2013 
眨一眨眼可為電子裝置供電開啟燈泡、手指頭一動即可打開上鎖的門戶，

不必成為特務都可擁有這些「特異功能」。巴西科學家維加（Katia Ve-

ga）將眼影、假眼睫毛和指甲加入無線電裝置，令美容與科技合二為一。

\section{The Creators Project}

Viral Style: Makeup That Drives Drones And A Bra That Tweets

http://thecreatorsproject.vice.com/blog/viral-style-drones

Fri, 25 Oct 2013

A weekly roundup of what's happening at the intersection of tech and fashion.

Drone-controlling beauty tech of the week.

\section{Golem}

Elektronische Wimpern lassen Dioden leuchten

http://www.golem.de/news/blinklifier-elektronische-wimpern-lassen-dioden-

leuchten-1310-102231.html

Fri, 18 Oct 2013

Blinklifier ist ein neuartiges Eingabegerät, das mit den Augen gesteuert wird: Es erkennt ein Augenzwinkern und löst eine Aktion aus. Gleichzeitig soll es die Träger verschönern.

\section{Imena}

Электронный макияж позволит управлять мобильными устройствами

http://www.imena.ua/blog/elektro-makiyazh

Fri, 18 Oct 2013

Американский инженер Катя Вега (Katia Vega) сообщила о создании

“электронного макияжа”, состоящего из микроэлементов, которые

располагаются на глазных веках.

\section{CNet}

Electronic makeup lets you control gadgets with a wink http://news.cnet.com/8301-17938_105-57607997-1/electronic-makeup-lets-youcontrol-gadgets-with-a-wink/

Fri, 18 Oct 2013

Fingernails embedded with RFID tags? Computer scientist Katia Vega creates Beauty Technology, a range of cosmetics and accessories that conduct electrici- 
ty and control devices.

\section{The Times}

Metallic make-up that turns on lights

http://www.thetimes.co.uk/tto/technology/article3897627.ece?CMP=OTH-gnws-

standard-2013_10_17

Fri, 18 Oct 2013

The hi-tech cosmetics were unveiled at an Interactive and Surface conference at the University of St Andrews

\section{IEEE}

Computer scientist Katia Vega has developed a set of conducting cosmetics that can be applied to your fingernails or eyelashes to control technology

https://www.facebook.com/photo.php?fbid=573082502746389\&set=a. 176108879 110422.62121.176104589110851\&type=1\&theater

Fri, 18 Oct 2013

Computer scientist Katia Vega has developed a set of conducting cosmetics that can be applied to your fingernails or eyelashes to control technology.

\section{PSFK}

Electronic Eyelashes control mobile devices with a wink

http://www.psfk.com/2013/10/electronic-eyelashes-control-devices.html

Thu, 17 Oct 2013

Beauty tech designer Katia Vega developed cosmetics that can activate various equipment

\section{Popsci}

A Tiny Helicopter Controlled With A Wink

http://www.popsci.com/article/gadgets/watch-tiny-helicopter-controlled-wink

Thu, 17 Oct 2013

Special metallic makeup could put the face back into "user interface."

\section{Mnn}

Electronic make-up lets you control the lights with a wink http://www.mnn.com/lifestyle/natural-beauty-fashion/stories/electronic-make-uplets-you-control-the-lights-with-a-wink 
Thu, 17 Oct 2013

Now you can look electric and, well, actually be electric too. Researchers have developed electronic makeup that turns your face into a remote control.

\section{Thomas net}

\section{Light Friday: 8 Mental Illnesses Caused by the Internet}

http://news.thomasnet.com/IMT/2013/10/18/light-friday-8-mental-illnesses-

caused-by-the-internet/

Thu, 17 Oct 2013

Wearable Beauty Technology Lights up a Room One engineer has found a way to infuse beauty with technology to create conducting cosmetics that are capable of activating electronics and levitating objects. Katia Vega, the makeup tech mastermind, is currently a Ph.D. candidate in computer science at Pontifical Catholic University of Rio de Janeiro in Brazil and has developed chemically metalized eyelashes, RFID nails, and makeup that "connect sensors, actuators and their connections in an attractive way that the wearer's observers would not notice the hidden circuit," Vega notes on her website.

\section{New Scientist}

Metallic make-up lets you launch drones with a wink http://www.newscientist.com/article/dn24412-metallic-makeup-lets-you-launchdrones-with-a-wink.html\#.UmVcDBAwdpd

Wed, 16 Oct 2013

When Katia Vega winks, strange things happen: a miniature drone takes to the air, or a hundred LEDs in her hair sparkle like a Christmas tree. It works because she has developed a range of conducting cosmetics that let her activate electronics with a flip of her eyelids

\section{Boing Boing}

Conductive cosmetics to control mobile devices

http://boingboing.net/2013/10/16/conductive-cosmetics-to-contro.html

Wed, 16 Oct 2013

Computer scientist Katia Vega has developed conductive eye shadow and false eyelashes that can be used to control wearable computers. For example, an extended blink could trigger your phone's camera. 


\section{Fast Company}

This Makeup Lets You Launch Drones With Just A Blink Of An Eye

http://www.fastcompany.com/3020130/fast-feed/this-makeup-lets-you-launchdrones-with-just-a-blink-of-an-eye

Wed, 16 Oct 2013

Brazilian scientist Katia Vega has developed cosmetics with the ability to launch a drone or open a door.

\section{Future Tech Report}

Using cosmetics to control gadgets

http://futuretechreport.com/post/64679126997/using-cosmetics-to-control-

gadgets-one-of-the

Mon, 21 Oct 2013

One of the most intriguing developments to come out of the recent ACM Interactive Tabletops and Surfaces Conference is new work from the Brazilian scientist, Katia Vega, who offered up something called "electro-cosmetics", or the field of research into controlling electronics using cosmetic make-up.

\section{Refinery 29}

This Is NOT Science Fiction: A Woman Can Control Drones With Her ... http://www.refinery29.com/2013/10/55603/metallic-makeup-controls-drones Fri, 18 Oct 2013 We can do a lot with our makeup: change our look, highlight a certain feature, attract attention...the list goes on. What our list doesn't include, though, is the ability to, um, control drones. That's apparently simply because we're not Katia Vega, a computer scientist who has developed makeup that can literally activate electronics. Wait, what?

\section{Gizmodo}

Electronic Make-Up Lets You Activate Gadgets By Blinking http://gizmodo.com/electronic-make-up-lets-you-activate-gadgets-by-blinkin1446288892

Thu, 17 Oct 2013

Ever wanted to a launch a fleet of killer drones with the blink of an eye? Good news, researchers have just the thing. 


\section{Stuff Tv}

Fully Charged: Enter the Matrix, Android PCs, and how to scramble ...

http://www.stuff.tv/gopro/fully-charged-fire-eating-how-scramble-drone-blink-eyeand/news

Wed, 16 Oct 2013

Ever wanted to a launch a fleet of killer drones with the blink of an eye? Good news, researchers have just the thing.

\section{Ubergizmo}

Makeup Gets Conductive

http://www.ubergizmo.com/2013/10/makeup-gets-conductive/

Fri, 18 Oct 2013

Putting on makeup might not be the same any more in the future, as wearable technology takes on a whole new level of interactivity. With the clever application of conductive makeup in common beauty items such as false eyelashes, nails and eyeshadow, computer scientist Katia Vega managed to figure out a way to make conductive elements as well as sensors part of transforming an ordinary makeup into gadget-activating remote controls.

\section{Apparata}

Elektronische make-up bestuurt gadgets met een knipoog

http://www.apparata.nl/nieuws/elektronische-make-up-bestuurt-gadgets-met-eenknipoog-3788

Wed, 16 Oct 2013

Dus je wilt je gadgets op afstand bedienen, maar bent te lui om de afstandsbediening te pakken en Google Glass kan je niet betalen. Gelukkig heeft je vrouw/vriendin een dikke laag make-up op en kan zo van kanaal wisselen. Wait, what?

\section{Globo}

Conheça sete criações inovadoras que saíram de universidades http://oglobo.globo.com/educacao/conheca-sete-criacoes-inovadoras-quesairam-de-universidades-9632117\#ixzz2iNPCMgPI Wed, 23 Oct 2013

A aluna do curso de doutorado do Departamento de Informática da PUC-Rio, 
Katia Vega, desenvolve pesquisas sobre o conceito de "Beauty Technology", que agrega tecnologia a diferentes partes do corpo humano. A pesquisadora já desenvolveu cílios postiços capazes de emitir comandos eletrônicos através do movimento do piscar dos olhos, como passar slides em uma apresentação, e criou unhas postiças com dispositivos que emitem comandos como acender luzes e abrir portas.

\section{Globo}

Feira com trabalhos tecnológicos da PUC-Rio deve atrair 75 mil visitantes http://g1.globo.com/globo-news/jornal-das-dez/videos/t/todos-os-videos/v/feiracom-trabalhos-tecnologicos-da-puc-rio-deve-atrair-75-mil-visitantes/2761613/ Wed, 23 Oct 2013

São trabalhos de alta tecnologia, muitos deles com iniciativas sustentáveis. Os projetos, protótipos e até produtos criados pelos alunos, será exibidos durante quatro dias na universidade.

\section{Tech tudo}

Pesquisadora cria sistema que controla objetos pelo movimento de olhos e dedos http://www.techtudo.com.br/noticias/noticia/2013/07/pesquisadora-cria-sistemaque-controla-objetos-pelo-movimento-de-olhos-e-dedos.html Mon, 8 Jul 2013

Ao menos uma vez na vida você quis poder controlar um objeto com um piscar de olhos, não é? Saiba que essa realidade está cada vez mais próxima. Uma pesquisa resultou na criação de cílios postiços e unhas de acrigel, capazes de controlar apresentações de slides, equipamentos de DJ, iluminação e uma infinidade de objetos. O estudo, desenvolvido na PUC-Rio, é feito pela peruana Kátia Vega, com supervisão do professor Hugo Fuks.

\section{CNN}

Bionic fashion: Wearable tech that will turn man into machine by 2015 http://edition.cnn.com/2013/07/25/tech/innovation/bionic-fashion-wearable-tech2015/index.html Mon, 5 Aug 2013

The field of wearable technology is rich with exploration of human emotion -- and 
headwear that would turn Padmé Amidala green with envy. The flirty Blinklifier is a concept by Tricia Flanagan and Katia Vega. It's fitted with LEDs that respond to specific eye-movement and could take flirting to a new level. Researchers hope the result will give people more visual clues about how their friends are feeling.

\section{Abril}

Google Glass - Por que ter um computador no corpo

http://info.abril.com.br/revista/extras/index.shtml?ed=330

Mon, 1 Jul 2013

Conectado à internet, o Google Glass é pioneiro de uma tendência que deve nos levar à computação de vestir

\section{Sensoree}

Move over Google Glass, we have Beauty Technology

http://sensoree.com/move-over-google-glass-we-have-beauty-technology/ Fri, 24 May 2013

Conductive make-up, magnetic finger nails, a blink controller that levitates objects with blinking? Take off my Google Glass and paint it on me!

\section{Globo}

Aluna da PUC-Rio cria cílios que controlam objetos ao piscar http://g1.globo.com/tecnologia/noticia/2013/04/aluna-da-puc-rio-cria-cilios-quecontrolam-objetos-ao-piscar.html Wed, 17 Apr 2013

Katia Vega recebeu o prêmio TEI Design Challenge, em Barcelona. Cílios usam tecnologia conhecida como 'computação vestível'.

Katia, que mora no Rio de Janeiro desde 2008, metalizou os cílios postiços com prata e outros elementos químicos para que eles parecessem pretos e naturais. Com o controle remoto de um pequeno orbitador escondido no bolso, Katia podia ativá-lo apenas ao piscar os olhos. Leia mais... 


\section{References}

1.Mann, S. (1998). Humanistic computing:"WearComp" as a new framework and application for intelligent signal processing. Proceedings of the IEEE, 86(11), 2123-2151.

2.Vega, K. F. C., \& Fuks, H. (2013). Empowering Electronic Divas through Beauty Technology. In Design, User Experience, and Usability. User Experience in Novel Technological Environments (pp. 237-245). Springer Berlin Heidelberg.

3.Tzeng, S. F., Chen, W. H., \& Pai, F. Y. (2008). Evaluating the business value of RFID: evidence from five case studies. International Journal of Production Economics, 112(2), 601-613.

4.Morris, R. L., Harary, S. B., Janis, J., Hartwell, J., \& Roll, W. G. (1978). Studies of communication during out-of-body experiences. Journal of the American Society for Psychical Research, 72(1), 1-21.

5.Weiser, M. (1991). The computer for the 21st century. Scientific american, 265(3), 94-104.

6.Streitz, N., Kameas, A., \& Mavrommati, I. (2007). The disappearing computer: interaction design, system infrastructures and applications for smart environments. Springer-Verlag.

7.Norman, D. A. (1999). The invisible computer: why good products can fail, the personal computer is so complex, and information appliances are the solution. MIT press.

8.Starner, T. E. (1999). Wearable computing and contextual awareness (Doctoral dissertation, Massachusetts Institute of Technology).

9.Hooke, R. (1965). Micrographia (Preface).

10.Ranck, J. (2012) The wearable computing market: a global analysis. Gigaom Pro.

11.Pearson, I. (2005). The Future of Fashion. Journal of the Communications Network, 4(2), 68.

12.Google (2014) Google Glass. Retrieved from http://www.google.com.br/glass/start/what-it-does/

13.Pebble (2014) Get Pebble. Retrieved from https://getpebble.com/

14.Lucy and Bart (2014) Evolution and Hock and Eyes. Retrieved from http://www.lucyandbart.blogspot.com.br/

15.Park, S. (2014) LED eyelashes Retrieved from http://soomipark.com/main/ 16.McRae, L. (2014) How can technology transform the human body? Retrieved from

http://www.ted.com/talks/lucy_mcrae_how_can_technology_transform_the_hu man_body.html

17.Clynes, M. E., \& Kline, N. S. (1960). Cyborgs and space. Astronautics, 14(9), 26-27.

18.Popular Science (1963). Must Tomorrow's Man Look Like This?.

19.Kurzweil, R. (2005). The singularity is near: When humans transcend biology. Penguin. 
20. Guga, J. (2011) Cyborg:From Science Fiction to Social Reality (Working Paper).

21. Caidin, M. (1974). Six Million Dollar Man.

22. Marcus, A., Norman, D. A., Rucker, R., Sterling, B., \& Vinge, V. (1992, June). Sci-fi at CHI: Cyberpunk novelists predict future user interfaces. In Proceedings of the SIGCHI conference on Human factors in computing systems (pp. 435-437). ACM.

23.Star Trek (1966). Locutus. Retrieved from http://www.startrek.com/database_article/locutus

24.Abawajy, J. H. (2009). Human-computer interaction in ubiquitous computing environments. International journal of pervasive computing and communications, 5(1), 61-77.

25.Sorabji, R. (1971). Aristotle on demarcating the five senses. The Philosophical Review, 55-79.

26.Kant, I., Guyer, P., \& Wood, A. W. (Eds.). (1998). Critique of pure reason. Cambridge University Press.

27.Mumford, M. D., Costanza, D.P., Connelly, M.S., \& Johnson, J.F. Item generation procedures and background data scales: Implications for construct and criterion-related validity. Personnel Psychology, 49, (1996), 360-398.

28.Singla, R., Chambayil, B., Khosla, A., \& Santosh, J. (2011). Comparison of SVM and ANN for classification of eye events in EEG. Journal of Biomedical Science \& Engineering, 4(1).

29.Lemon, R. (1988). The output map of the primate motor cortex. Trends in neurosciences, 11(11), 501-506.

30.Tsakiris, M., Schütz-Bosbach, S., \& Gallagher, S. (2007). On agency and body-ownership: Phenomenological and neurocognitive reflections. Consciousness and cognition, 16(3), 645-660.

31.Kawaguchi, T., Rizon, M., \& Hidaka, D. (2005). Detection of eyes from human faces by Hough transform and separability filter. Electronics and Communications in Japan (Part II: Electronics), 88(5), 29-39.

32.Lai, K., Konrad, J., \& Ishwar, P. (2012, April). A gesture-driven computer interface using Kinect. In Image Analysis and Interpretation (SSIAI), 2012 IEEE Southwest Symposium on (pp. 185-188). IEEE.

33.Mistry, P., Maes, P., \& Chang, L. (2009, April). WUW-wear Ur world: a wearable gestural interface. In CHI'09 extended abstracts on Human factors in computing systems (pp. 4111-4116). ACM.

34.Harrison, C., Ramamurthy, S., \& Hudson, S. E. (2012). On-body interaction: armed and dangerous. In Proceedings of the Sixth International Conference on Tangible, Embedded and Embodied Interaction (pp. 69-76). ACM.

35.Windmiller, J. R., \& Wang, J. (2013). Wearable electrochemical sensors and biosensors: a review. Electroanalysis, 25(1), 29-46.

36.Tharion, W. J., Buller, M. J., Karis, A. J., \& Mullen, S. P. (2007, October). Acceptability of a wearable vital sign detection system. In Proceedings of the Human Factors and Ergonomics Society Annual Meeting (Vol. 51, No. 17, pp. 1006-1010). SAGE Publications.

37.Bitarello, B., Fuks, H., \& Queiroz, J. (2011, January). New technologies for dynamic tattoo art. In Proceedings of the fifth international conference on Tangible, embedded, and embodied interaction (pp. 313-316). ACM.

38.Schlatka B. (October 2012) Breaking Free. Future Materials Magazine. 
39.Mc10 (2014) Retrieved from http://www.mc10inc.com/companyinformation/technology

40.Rotter, P., Daskala, B., \& Compano, R. (2008). RFID implants: Opportunities and and challenges for identifying people. Technology and Society Magazine, IEEE, 27(2), 24-32.

41.Foster, K. R., \& Jaeger, J. (2007). RFID inside. Spectrum, IEEE, 44(3), 24-29. 42. Ding L. (2014) Retrieved from http://dlulin.com/projects/digital-eyeshadow/

43.Salvucci, D. D., \& Anderson, J. R. (2001). Automated eye-movement protocol analysis. Human-Computer Interaction, 16(1), 39-86.

44.Singla, R., Chambayil, B., Khosla, A., \& Santosh, J. (2011). Comparison of SVM and ANN for classification of eye events in EEG. Journal of Biomedical Science \& Engineering, 4(1).

45.Saponas, T. S., Tan, D. S., Morris, D., Balakrishnan, R., Turner, J., \& Landay, J. A. (2009, October). Enabling always-available input with muscle-computer interfaces. In Proceedings of the 22nd annual ACM symposium on User interface software and technology (pp. 167-176). ACM.

46.Kim, J., Mastnik, S., \& André, E. (2008, January). EMG-based hand gesture recognition for realtime biosignal interfacing. In Proceedings of the 13th international conference on Intelligent user interfaces (pp. 30-39). ACM.

47.Bulling, A., Roggen, D., \& Tröster, G. (2008, September). It's in your eyes: towards context-awareness and mobile HCI using wearable EOG goggles. In Proceedings of the 10th international conference on Ubiquitous computing (pp. 84-93). ACM.

48.Horng, W. B., Chen, C. Y., Chang, Y., \& Fan, C. H. (2004, March). Driver fatigue detection based on eye tracking and dynamk, template matching. In Networking, Sensing and Control, 2004 IEEE International Conference on (Vol. 1, pp. 7-12). IEEE.

49.Krolak, A., \& Strumiłło, P. (2006). Fatigue monitoring by means of eye blink analysis in image sequences. ICSES, 1, 219-222.

50.Zhou, Z.H., Geng, X.: Projection functions for eye detection. Pattern Recognit. 37(5), 1049-1056 (2004)

51.Królak, A., and Strumiłło, P. Eye-blink detection system for human-computer interaction. Universal Access in the Information Society, 11(4), (2012), 409-419.

52.Kanade, T., Cohn, J. F., \& Tian, Y. (2000). Comprehensive database for facial expression analysis. In Automatic Face and Gesture Recognition, 2000. Proceedings. Fourth IEEE International Conference on (pp. 46-53). IEEE.

53.Izard, C. E. (1979). The Maximally Discriminitive Facial Movements Coding System, MAX. University of Delaware.

54.Ekman, P., \& Friesen, W. V. (1978). Facial action coding system: A technique for the measurement of facial movement. Palo Alto.

55.Scherer, K. R., \& Ekman, P. (Eds.). (1982). Handbook of methods in nonverbal behavior research (Vol. 2, pp. 970-974). Cambridge: Cambridge University Press.

56.Rantanen, V., Venesvirta, H., Spakov, O., Verho, J., Vetek, A., Surakka, V., \& Lekkala, J. (2013). Capacitive Measurement of Facial Activity Intensity.

57.Manabe, D. (April, 2010) Daito manabe. Retrieved from http://www.daito.ws/. 58.Wimmer, R., \& Echtler, F. (2013, April). Exploring the benefits of fingernail displays. In CHI'13 Extended Abstracts on Human Factors in Computing Systems (pp. 937-942). ACM. 
59.Su, C. H., Chan, L., Weng, C. T., Liang, R. H., Cheng, K. Y., \& Chen, B. Y. (2013, April). NailDisplay: bringing an always available visual display to fingertips. In Proceedings of the 2013 ACM annual conference on Human factors in computing systems (pp. 1461-1464). ACM.

60.Weigel, M., \& Steimle, J. (2013). Fingernail displays: Handy displays at your fingertips. CHI'13 Extended Abstracts on Human Factors in Computing Systems, 937-942.

61.Fukumoto, M., \& Suenaga, Y. (1994, April). "FingeRing": a full-time wearable interface. In Conference companion on Human factors in computing systems (pp. 81-82). ACM.

62.Ketabdar, H., Moghadam, P., \& Roshandel, M. (2012, July). Pingu: A new miniature wearable device for ubiquitous computing environments. In Complex, Intelligent and Software Intensive Systems (CISIS), 2012 Sixth International Conference on (pp. 502-506). IEEE.

63.Ashbrook, D., Baudisch, P., \& White, S. (2011, May). Nenya: subtle and eyesfree mobile input with a magnetically-tracked finger ring. In Proceedings of the SIGCHI Conference on Human Factors in Computing Systems (pp. 2043-2046). ACM.

64.Harrison, C., \& Hudson, S. E. (2009, October). Abracadabra: wireless, highprecision, and unpowered finger input for very small mobile devices. In Proceedings of the 22nd annual ACM symposium on User interface software and technology (pp. 121-124). ACM.

65.Hinckley, K. (2002). Input technologies and techniques. The human-computer interaction handbook: fundamentals, evolving technologies and emerging applications, 151-168.

66.Lepinski, G. J., Grossman, T., \& Fitzmaurice, G. (2010, April). The design and evaluation of multitouch marking menus. In Proceedings of the SIGCHI Conference on Human Factors in Computing Systems (pp. 2233-2242). ACM.

67.Dietz, P., \& Leigh, D. (2001, November). DiamondTouch: a multi-user touch technology. In Proceedings of the 14th annual ACM symposium on User interface software and technology (pp. 219-226). ACM.

68.Pentland, A. P. (1998). Wearable intelligence. Scientific American, Incorporated.

69.Jablonski, N. G. (2013). Skin: A natural history. Univ of California Press.

70.Albano, R. E. (2004). Skin, hair, and nails: structure and function (Vol. 26). CRC Press.

71.Kapur, A., Kapur, A., Virji-Babul, N., Tzanetakis, G., \& Driessen, P. F. (2005). Gesture-based affective computing on motion capture data. In Affective Computing and Intelligent Interaction (pp. 1-7). Springer Berlin Heidelberg

72.Gunes, H., \& Piccardi, M. (2005, July). Automatic visual recognition of face and body action units. In Information Technology and Applications, 2005. ICITA 2005. Third International Conference on (Vol. 1, pp. 668-673). IEEE. 73.van Duinen, H., \& Gandevia, S. C. (2011). Constraints for control of the human hand. The Journal of physiology, 589(23), 5583-5593.

74.Mistry, P., Ishii, K., Inami, M., \& Igarashi, T. (2010, October). Blinkbot: look at, blink and move. In Adjunct proceedings of the 23nd annual ACM symposium on User interface software and technology (pp. 397-398). ACM.

75.Grauman, K., Betke, M., Lombardi, J., Gips, J., \& Bradski, G. R. (2003). Communication via eye blinks and eyebrow raises: Video-based humancomputer interfaces. Universal Access in the Information Society, 2(4), 359-373. 
76.Park, K. S., \& Lee, K. T. (1996). Eye-controlled human/computer interface using the line-of-sight and the intentional blink. Computers \& industrial engineering, 30(3), 463-473.

77.Miles, W. R. (1931). Elevation of the eye-balls on winking. Journal of Experimental Psychology, 14(4), 311.

78.TEI Design Challenge (2013) Superhero Retrieved from http://www.teiconf.org/13/dc

79.Lathem, P. A., Gregorio, T. L., \& Garber, S. L. (1985). High-level quadriplegia: An occupational therapy challenge. The American Journal of Occupational Therapy, 39(11), 705-714.

80.Sipski, M. L., \& Richards, J. S. (2006). Spinal cord injury rehabilitation: state of the science. American Journal of Physical Medicine \& Rehabilitation, 85(4), 310-342.

81.Mouth exerciser (2014) Retrieved from http://www.sickchirpse.com/weirdjapanese-beauty-techniques/

82.Sydney VIVID festival (Australia, 2013). Haptic Interface Pop-Up exhibition. 83.Asian Premiere of Multimedia Art: New York Paris Hong Kong Change your Perception (Hong Kong, 2013).

84.JMGA 15th Biennial Conference Participation + Exchange. Participate Exhibtion. (Australia, 2012).

85.Haptic Interface Exhibition (Hong Kong, 2012). Project Blinklifier.

86.Beyond Wearable (China, 2012).

87.Conversatorio Fundación Telefónica. Arte y Estética en Wearable Computers

(Peru, 2013). Projects: Arcana, Gimmickiano, AquaDJing.

88.TEI 2013 Design Challenge (Spain, 2013). Projects: Superhero.

89.Bare Coductive (2014). Retrieved from http://www.bareconductive.com/ 90.Vega, K., \& Fuks, H. (2014). Beauty Technology: Body Surface Computing.

In Computer, vol. 47, no. 4, pp. 71-75, Apr. 2014, doi:10.1109/MC.2014.81

91.Vega, K. (2013, February). Exploring the power of feedback loops in wearables computers. In Proceedings of the 7th International Conference on Tangible, Embedded and Embodied Interaction (pp. 371-372). ACM.

92.Jain, A. K., \& Li, S. Z. (2005). Handbook of face recognition. New York: springer.

93.Vega, K., \& Fuks, H. (2013, October). Beauty technology as an interactive computing platform. In Proceedings of the 2013 ACM international conference on Interactive tabletops and surfaces (pp. 357-360). ACM.

94.Lin, M., \& Li, B. (2010, October). A wireless EOG-based human computer interface. In Biomedical Engineering and Informatics (BMEI), $20103 \mathrm{rd}$ International Conference on (Vol. 5, pp. 1794-1796). IEEE.

95.Curran, E., Sykacek, P., Stokes, M., Roberts, S. J., Penny, W., Johnsrude, I., \& Owen, A. M. (2004). Cognitive tasks for driving a brain-computer interfacing system: a pilot study. Neural Systems and Rehabilitation Engineering, IEEE Transactions on, 12(1), 48-54.

96.Tanaka, K., Matsunaga, K., Kanamori, N., Hori, S., \& Wang, H. O. (2003, Ju1y). Electroencephalogram-based control of a mobile robot. In Computational Intelligence in Robotics and Automation, 2003. Proceedings. 2003 IEEE International Symposium on (Vol. 2, pp. 688-693). IEEE.

97.Fabiani, G. E., McFarland, D. J., Wolpaw, J. R., \& Pfurtscheller, G. (2004). Conversion of EEG activity into cursor movement by a brain-computer interface 
(BCI). Neural Systems and Rehabilitation Engineering, IEEE Transactions on, 12(3), 331-338.

98.Gallagher, S. (2000). Self reference and schizophrenia. Exploring the self, 203239.

99.Tsakiris, M., Prabhu, G., \& Haggard, P. (2006). Having a body $<\mathrm{i}>$ versus $</ \mathrm{i}>$ moving your body: How agency structures body-ownership. Consciousness and cognition, 15(2), 423-432.

100.Tsakiris, M., Schütz-Bosbach, S., \& Gallagher, S. (2007). On agency and body-ownership: Phenomenological and neurocognitive reflections. Consciousness and cognition, 16(3), 645-660.

101.Rinn, W. E. (1984). The neuropsychology of facial expression: a review of the neurological and psychological mechanisms for producing facial expressions. Psychological bulletin, 95(1), 52.

102.Duchenne, G. B. (1990). The mechanism of human facial expression. Cambridge university press.

103.Ekman, P., Roper, G., \& Hager, J. C. (1980). Deliberate facial movement. Child Development, 51(3), 886-891.

104.Gosselin, P., Perron, M., \& Beaupré, M. (2010). The voluntary control of facial action units in adults. Emotion, 10(2), 266.

105.Vega, K.: Kinisi (2014). Retrieved from https://www.youtube.com/watch?v=7JrRo1U7c5o/.

106.Lathem, P. A., Gregorio, T. L., \& Garber, S. L. (1985). High-level quadriplegia: An occupational therapy challenge. The American Journal of Occupational Therapy, 39(11), 705-714.

107.Sipski, M. L., \& Richards, J. S. (2006). Spinal cord injury rehabilitation: state of the science. American Journal of Physical Medicine \& Rehabilitation, 85(4), 310-342.

108.Willingham, D. B. (1998). A neuropsychological theory of motor skill learning. Psychological review, 105(3), 558.

109.Card, S. K., Mackinlay, J. D., and Robertson, G. G. (1991). A morphological analysis of the design space of input devices. ACM Transactions on Information Systems (TOIS), 9(2), 99-122.

110.Rekimoto, J. (2001). Gesturewrist and gesturepad: Unobtrusive wearable interaction devices. In Wearable Computers, 2001. Proceedings. Fifth International Symposium on (pp. 21-27). IEEE.

111.Tzeng, S. F., Chen, W. H., \& Pai, F. Y. (2008). Evaluating the business value of RFID: evidence from five case studies. International Journal of Production Economics, 112(2), 601-613.

112.ID Innovations (2005), ID Series Datasheet. Retrieved from https://www.sparkfun.com/datasheets/Sensors/ID-12-Datasheet.pdf

113.Roberts, C. M. (2006). Radio frequency identification (RFID). Computers \& Security, 25(1), 18-26.

114.Want, R. (2006). An introduction to RFID technology. Pervasive Computing, IEEE, 5(1), 25-33.

115.Russell, J. A., \& Fernández-Dols, J. M. (Eds.). (1997). The psychology of facial expression. Cambridge university press. 